\title{
Simultaneous analysis of large-scale RNAi screens for pathogen entry
}

\author{
Pauli Rämö ${ }^{1 \dagger}$, Anna Drewek ${ }^{2 \dagger}$, Cécile Arrieumerlou ${ }^{13}$, Niko Beerenwinkel ${ }^{4,5}$, Houchaima Ben-Tekaya ${ }^{1}$, \\ Bettina Cardel ${ }^{3}$, Alain Casanova ${ }^{1}$, Raquel Conde-Alvarez ${ }^{7}$, Pascale Cossart ${ }^{6}$, Gábor Csúcs ${ }^{11}$, Simone Eicher ${ }^{1}$, \\ Mario Emmenlauer ${ }^{1}$, Urs Greber ${ }^{3}$, Wolf-Dietrich Hardt ${ }^{9}$, Ari Helenius ${ }^{8}$, Christoph Kasper ${ }^{1}$, Andreas Kaufmann ${ }^{11}$, \\ Saskia Kreibich ${ }^{9}$, Andreas Kühbacher ${ }^{6}$, Peter Kunszt ${ }^{14}$, Shyan Huey Low ${ }^{1}$, Jason Mercer ${ }^{8}$, Daria Mudrak ${ }^{3}$, \\ Simone Muntwiler ${ }^{1}$, Lucas Pelkmans ${ }^{3}$, Javier Pizarro-Cerdá ${ }^{6}$, Michael Podvinec ${ }^{12}$, Eva Pujadas ${ }^{12}$, Bernd Rinn ${ }^{4,5}$, \\ Vincent Rouilly ${ }^{12}$, Fabian Schmich ${ }^{4}$, Juliane Siebourg-Polster ${ }^{4}$, Berend Snijder ${ }^{3}$, Michael Stebler ${ }^{11}$, Gabriel Studer ${ }^{1}$, \\ Ewa Szczurek ${ }^{4,5}$, Matthias Truttmann ${ }^{1}$, Christian von Mering ${ }^{3}$, Andreas Vonderheit ${ }^{10}$, Artur Yakimovich ${ }^{3}$, \\ Peter Bühlmann ${ }^{2}$ and Christoph Dehio ${ }^{1^{*}}$
}

\begin{abstract}
Background: Large-scale RNAi screening has become an important technology for identifying genes involved in biological processes of interest. However, the quality of large-scale RNAi screening is often deteriorated by off-targets effects. In order to find statistically significant effector genes for pathogen entry, we systematically analyzed entry pathways in human host cells for eight pathogens using image-based kinome-wide siRNA screens with siRNAs from three vendors. We propose a Parallel Mixed Model (PMM) approach that simultaneously analyzes several non-identical screens performed with the same RNAi libraries.

Results: We show that PMM gains statistical power for hit detection due to parallel screening. PMM allows incorporating siRNA weights that can be assigned according to available information on RNAi quality. Moreover, PMM is able to estimate a sharedness score that can be used to focus follow-up efforts on generic or specific gene regulators. By fitting a PMM model to our data, we found several novel hit genes for most of the pathogens studied.

Conclusions: Our results show parallel RNAi screening can improve the results of individual screens. This is currently particularly interesting when large-scale parallel datasets are becoming more and more publicly available. Our comprehensive siRNA dataset provides a public, freely available resource for further statistical and biological analyses in the high-content, high-throughput siRNA screening field.
\end{abstract}

Keywords: High-throughput high-content RNAi screening, Pathogen entry, Linear mixed model, Hit detection

\section{Background}

Large-scale RNAi screening is a widely used technology to knock-down expressions of genes and study their protein function in a biological process of interest [1-5]. In several published studies in the field of infection biology, cells perturbed with siRNAs were exposed to pathogens and differences in phenotypic outcomes were measured in order to identify the genes involved in successful infection or to

\footnotetext{
* Correspondence: christoph.dehio@unibas.ch

'Equal contributors

${ }^{1}$ Focal Area Infection Biology, Biozentrum, University of Basel,

Klingelberstrasse 70, CH-4056 Basel, Switzerland

Full list of author information is available at the end of the article
}

develop functional models of host signaling and trafficking pathways [6-9].

RNAi libraries are mostly sold in formats containing enough material for numerous large-scale screens. Therefore, several large-scale siRNA screens are typically performed using the same libraries within a unit such as a university or company in order to optimize material costs and to simplify plate handling. However, parallel screens are typically performed and analyzed separately without common protocols or analysis pipelines. Therefore, comparing results between the screens is challenging. Co-operative efforts, such as assays using common key parameters for imaging and data analyses, could enable to

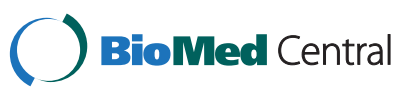

C 2014 Rämö et al.; licensee BioMed Central. This is an Open Access article distributed under the terms of the Creative Commons Attribution License (http://creativecommons.org/licenses/by/4.0), which permits unrestricted use, distribution, and reproduction in any medium, provided the original work is properly credited. The Creative Commons Public Domain Dedication waiver (http://creativecommons.org/publicdomain/zero/1.0/) applies to the data made available in this article unless otherwise stated. 
produce more comparable results and gain parallel information for each individual screen. In the field of RNAi screening, there has been progress in relation to the standardization of data publication formats, in particular in the context of the "Minimum Information About an RNAi Experiment” (MIARE, http://miare.sourceforge.net) and GenomeRNAi [10] efforts. However, the provided metadata information and data analysis approaches are often diverse so that data comparison between the screens from different laboratories is very difficult.

Poor reproducibility rates of large-scale RNAi screens are a common concern. They are mostly caused by strong off-target effects from particular siRNAs [11-16]. Strategies have been proposed to alleviate the confounding effects of RNAi screens, including experimental $[17,18]$ and statistical approaches [9,19-22]. In this study, we aim to use the parallel screening structure in order to gain statistical power for hit selection in large-scale RNAi screens. We generated high-content siRNA datasets that are uniquely comprehensive in terms of the siRNA libraries and various pathogens used. We employed highly unified protocols for parallel screens and common data analysis pipelines to allow a direct comparison between the readouts of different pathogen screens. In addition to obtain a list of hits for individual pathogens, our aim was to discover shared mechanisms between pathogens. To this purpose, we propose a new statistical method - the Parallel Mixed Model (PMM). Our approach simultaneously takes into account the knock-down effects of several non-identical screens performed in parallel with the same RNAi libraries. Additionally, the PMM provides a local False Discovery Rate (FDR) for every gene, resulting in a probability estimate that a gene is a false positive. We will show that the model improves statistical power thanks to parallel screening and that it yields stable hits, novel to the studied pathogens, without compromising the detection of unique hits for any given single screen.

\section{Results and discussion}

\section{High-content siRNA screening}

Our InfectX consortium, consisting of eleven research groups, generated kinome-wide siRNA screens for five bacterial pathogens (Bartonella henselae, Brucella abortus, Listeria monocytogenes, Salmonella typhimurium, and Shigella flexneri) and three viruses (Adenovirus, Rhinovirus, and Vaccinia virus) and systematically analyzed the biological pathways leading to successful infection in human host cells (Figure 1). This choice of bacterial and viral pathogens covered a wide variety of mechanism to invade host cells. B. henselae, for example, invades host cells by invasome structures [23], the pathogens S. typhimurium and S. flexneri use the trigger mechanism, while L. monocytogenes uses the zipper mechanism [24]. Adenovirus and Rhinovirus enter by a dynamin and clathrin dependent pathway [25] and Vaccinia virus by macropinocytosis [26].

We conducted the screens in a highly parallel manner under one common protocol for all eight pathogens. We carried out all screens in the same HeLa ATCC-CCL-2 cell line and with the same reagent batches of shared providers. The set of 826 targeted genes comprised almost the whole kinome, plus selected kinome-associated genes, and we targeted each gene by a total of eleven independent siRNAs coming from three manufactures: Ambion (Silencer Select) with 3 siRNAs per gene, Qiagen (Human Kinase siRNA Set V4.1) with 4 siRNAs per gene and Dharmacon (Human ON-TARGETpIus) with 4 siRNAs per gene. Additionally, we performed screens where we targeted each kinase with a pool of the four Dharmacon siRNAs (Human ON-TARGETpIus SMARTpooI). However, not all of the 826 genes have a full set of 11 siRNAs and 1 siRNA pool available. Depending on the pathogen and library, we independently repeated the screens one to six times as replicates (see Additional file 1: Table S1). To obtain an optimal dynamic range of infectivity, we chose the pathogen dose and entry time to be pathogen specific (see Additional file 1: Table S2). We fixed and stained the cells using DAPI or Hoechst to detect nuclei, fluorescent labeled phalloidin to detect actin filaments and the cell body, and a pathogen specific marker to detect infected cells. In a final step, we imaged the screens using microscopes of the same brand. Thus, we only permitted deviations from the common protocols when the infection assay required it.

We separately optimized image analysis for each pathogen and established for each pathogen a list of image features that described the phenotypes of infected cells. For example, for S. flexneri, we chose as one feature the RFP intensity of the extracted bacteria objects and for L. monocytogenes the mean Cy3 intensity of the cell (see Figure 1A and Additional file 1). In the next step, we classified the cells in each well as infected or uninfected with a Decision Tree Infection Scoring (DTIS) algorithm (see Additional file 1) and obtained a rate of infection per well (infection index) (Figures 1B-C). Besides assay-specific readouts the image analysis also provided several assay-independent readouts (e.g. cell number). We alleviated possible batch effects, dependencies to the population context, and further experimental confounders by data normalization (see Additional file 1) [27-32]. We performed all analyses presented in this paper with the normalized infection index readout, unless otherwise stated.

\section{Data reproducibility}

Our data confirmed the reported [20] low reproducibility rates of siRNA data originating from different siRNAs targeting the same genes. The normalized infection indices of two different siRNA sets targeting the same genes 


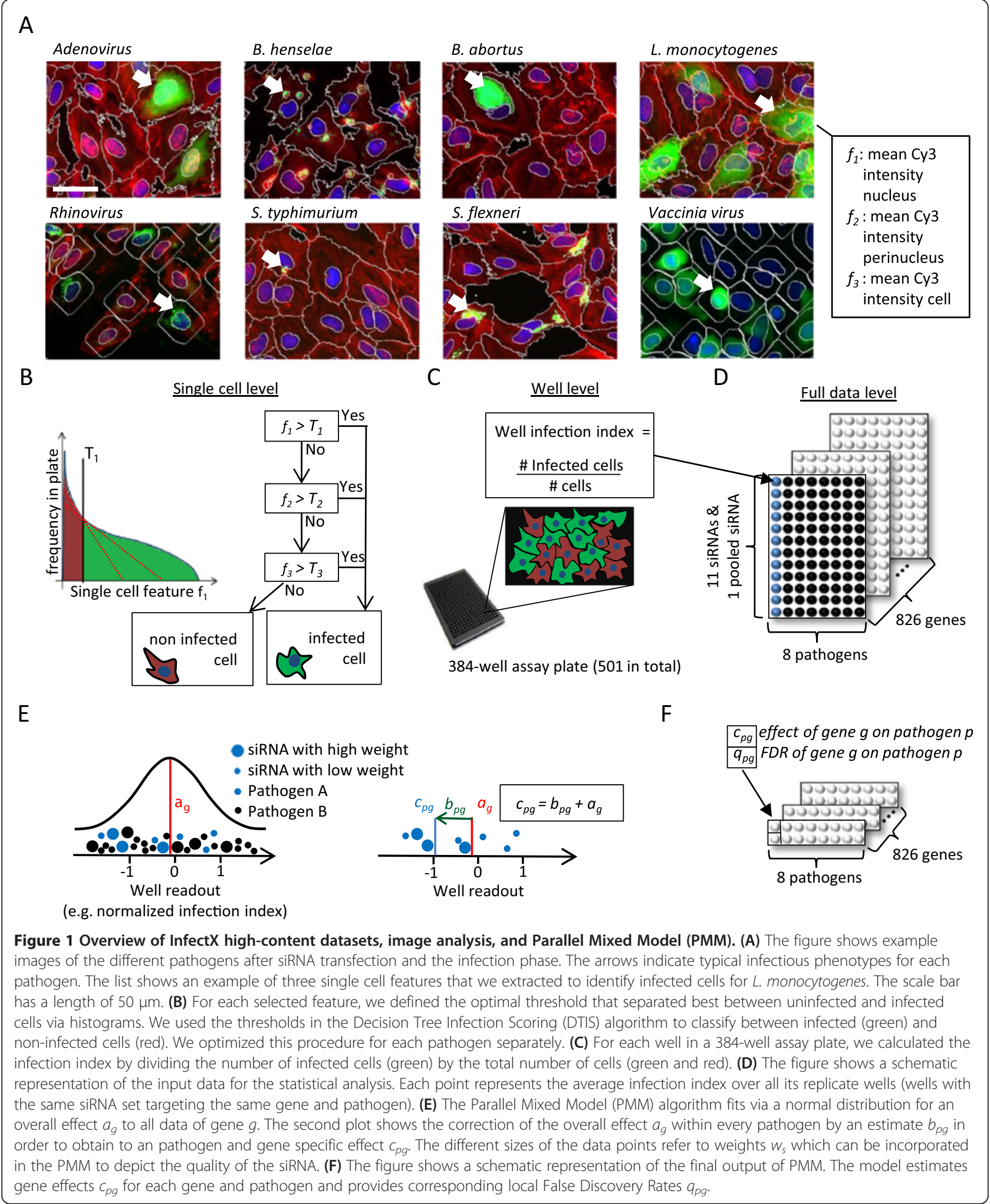

showed a Pearson correlation coefficient $R$ between 0 and 0.2 depending on the screens (Figure 2B). Adding independent siRNAs to the screen yielded an increase in the correlation coefficients, but the correlation still stayed at an unsatisfactory level, even with six separate siRNAs targeting each gene ( $R$ was between $0.1-0.4$ in 

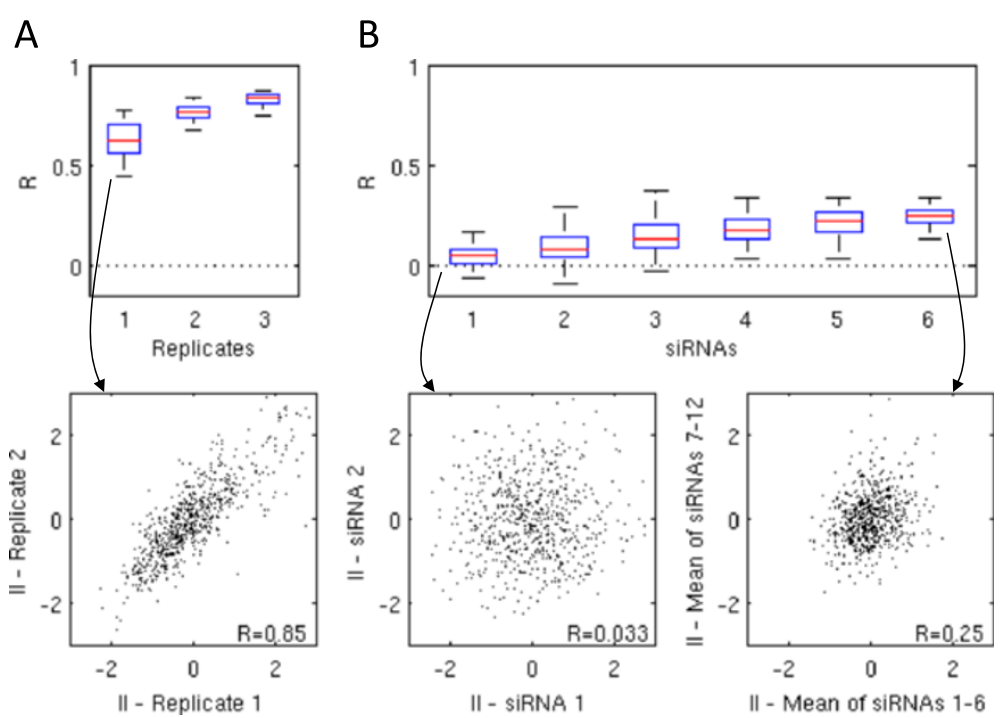

Figure 2 Using more siRNAs adds power and yields reproducible results. (A) The three boxplots show Pearson correlation coefficients $R$ between screens performed using the same siRNA set. The numbers 1 to 3 correspond to the total number of replicate screens that we averaged and compared to another distinct set of replicate screens, averaged over the same number. We resampled the replicate screens up to 500 times. The scatter plot shows an example for the correlation of infection indices from the duplicate of Adenovirus Dharmacon pooled screen.

(B) The set of six boxplots shows the Pearson correlation coefficients of the averaged readouts from 1 to 6 siRNA sets. The scatter plots depict the correlation of infection indices for Adenovirus, the first between two different single siRNAs and the second between each an average over six siRNAs.

averaged and separate sets of six independent siRNAs). In contrast, replicate screens (screens performed using the same protocols and siRNA set, but performed at a different time) were reproducible ( $R$ was between $0.5-$ 0.9 ) (Figure 2A). For practical reasons, assuming a similar assay quality as ours, performing screens in duplicates seems sufficient since having more replicates does not improve the data to a great extent (Figure 2A). On the other hand, performing screens at least in duplicates is necessary for quality control and performing only single screens is therefore not recommendable. The cell number readouts (see Additional file 1: Figure S4) showed qualitatively similar results for data reproducibility. In summary, the main error source in our siRNA screening was the bias caused by varying specificity of siRNAs and not by technical variability of the screens.

\section{Parallel Mixed Model (PMM)}

Assuming that the sources of variability between different siRNAs targeting the same gene are statistically independent, we can benefit from the fact that the true signal is enhanced by using more siRNAs targeting the individual genes [17] (Figure 2B). In order to increase the statistical power of individual siRNA screens, we performed screens with 11 siRNAs (and one pool of siRNAs) targeting each gene. Moreover, when using the parallel structure in the data and combining data points from all pathogen screens together, we reached $8 \times 12=96$ data points for every gene (averaging over the replicate screens). We propose the Parallel Mixed Model (PMM) as a suitable approach to model the distribution of the siRNA readouts using all data together, including all available siRNAs and pathogen screens.

PMM is composed of a linear mixed model and an assessment of the local False Discovery Rate (FDR) (Figure 1E-F). The linear mixed model is an extension of the ordinary linear model by random effects [33]. In particular, random effects are not determined by fixed coefficients, but by Gaussian distributions. Therefore, we can incorporate the variation among the siRNAs in form of random effects and estimate all effects for different pathogens simultaneously. To be more precise, the linear mixed model consists of a fixed effect $\mu_{p}$ for pathogen $p$ and two random effects $a_{g}$ for gene $g$ and $b_{p g}$ as a correction term for gene $g$ within pathogen $p$ :

$$
y_{p g s}=\mu_{p}+a_{g}+b_{p g}+\varepsilon_{p g s}
$$

where $y_{p g s}$ denotes the readout (for example the normalized infection index of a well) of pathogen $p$ and gene $g$ knocked-down with siRNA $s$ and $\varepsilon_{p g s}$ denotes the unobserved error term. We fitted the linear mixed model by using the "lmer" function from the "lme4" R-package [34]. The sum of two random effects $a_{g}$ and $b_{p g}$ describes the total effect of the siRNAs within pathogen $p$. We 
define the estimated effect $c_{p g}$ for gene $g$ within pathogen $p$ as

$$
c_{p g}=a_{g}+b_{p g} .
$$

A positive estimated $c_{p g}$ effect means that the infection level was enhanced if the corresponding gene $g$ is knocked down. A negative effect means that the infection level was reduced. To distinguish hit genes, PMM provides as second step an estimate $q_{p g}$ of the local False Discovery Rate (FDR). We computed the local False Discovery Rate using the approach presented in [59] and the "locfdr" function in the R-package of the same name [35]. We assigned the local False Discovery Rate to every gene and interpreted it as the probability describing how likely the corresponding gene is a false discovery (see Methods for more details). The PMM method is published as "PMM" R-package on the InfectX dataaccess page.

As a first verification for the increase in power by simultaneously using the parallel screening structure, we resampled datasets, each consisting of a fixed number of siRNAs and pathogens, and fitted the PMM, respectively the Moderated T-Test (MTT) [36] for the case of one pathogen (see Methods for details). We evaluated the mean and variation (i.e. stability) of the ranks in the ordered lists of genes based on their estimated $c_{p g}$ values over 1000 resampling runs for $M E T$ (a known effector gene for L. monocytogenes [37]), MTOR (a role of MTOR in the infection pathways of several pathogens has already been established [6,15,38]) and a non-hit $A L K$ as control (Figure 3). The results showed, in particular in the case of MTOR, that the rank and its stability improved by simultaneously using more siRNAs and pathogens. In the case of $M E T$ the use of parallel screens did not cause an increase in statistical power, since $M E T$ was a hit for $L$. monocytogenes only. However, for MET there was no reduction of statistical power either. These examples already indicated that the parallel screening structure and PMM can be used to more reliably discover expected effector genes even in the case where only a fraction of effector genes is shared between the screens.

\section{Analysis of siRNA libraries}

PMM allows the assignment of weights to each siRNA (see Methods). With weighting, we can assign more power to siRNAs that are estimated to have little off-target effects and strong knock-down efficiencies. Within this study, we weighted siRNAs according to the reproducibility in terms of correlation of their corresponding library to other libraries (Figure 4A). There are several potential other ways how weights could be determined. However, we did not follow them further within the context of this paper.

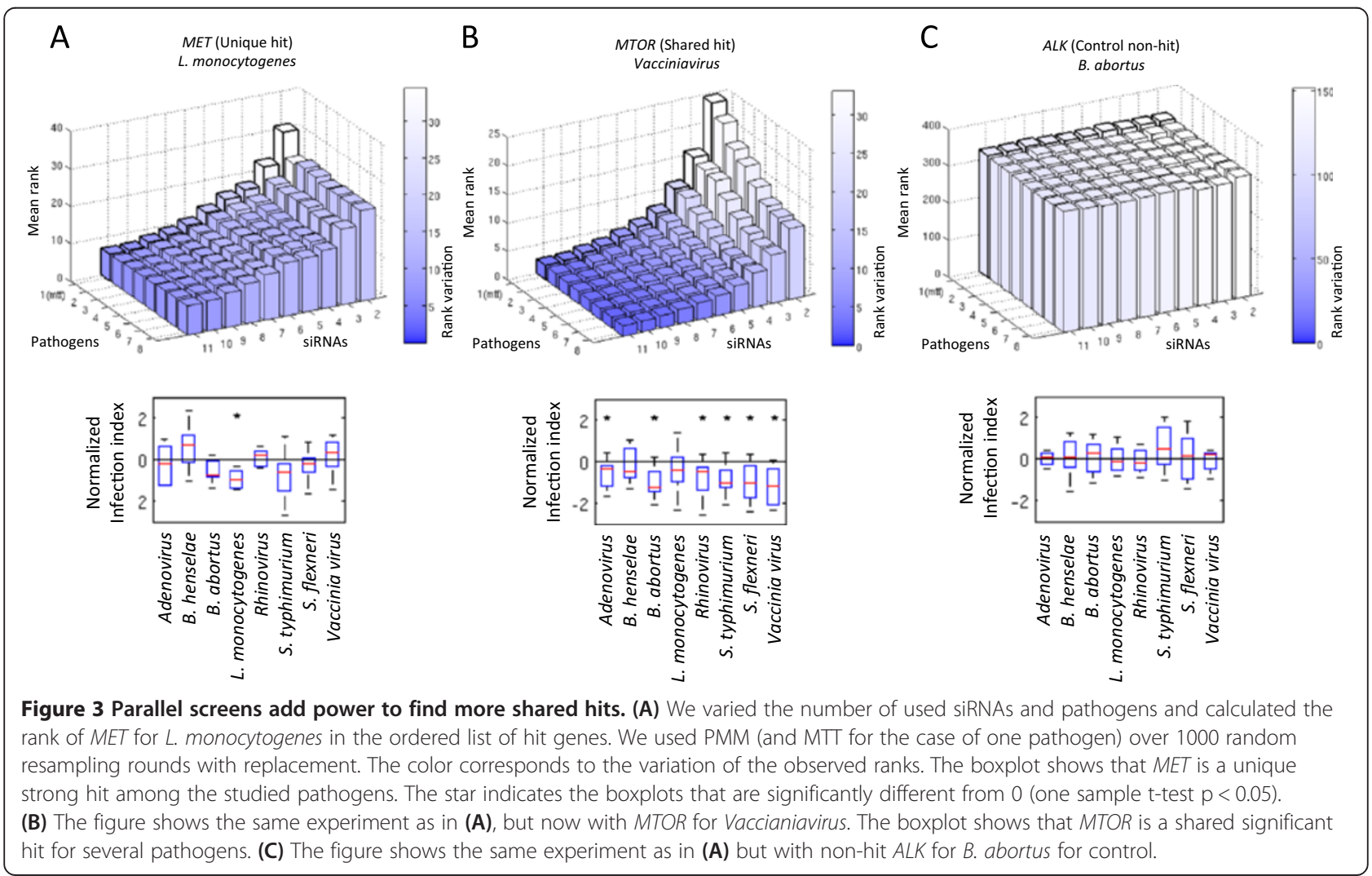




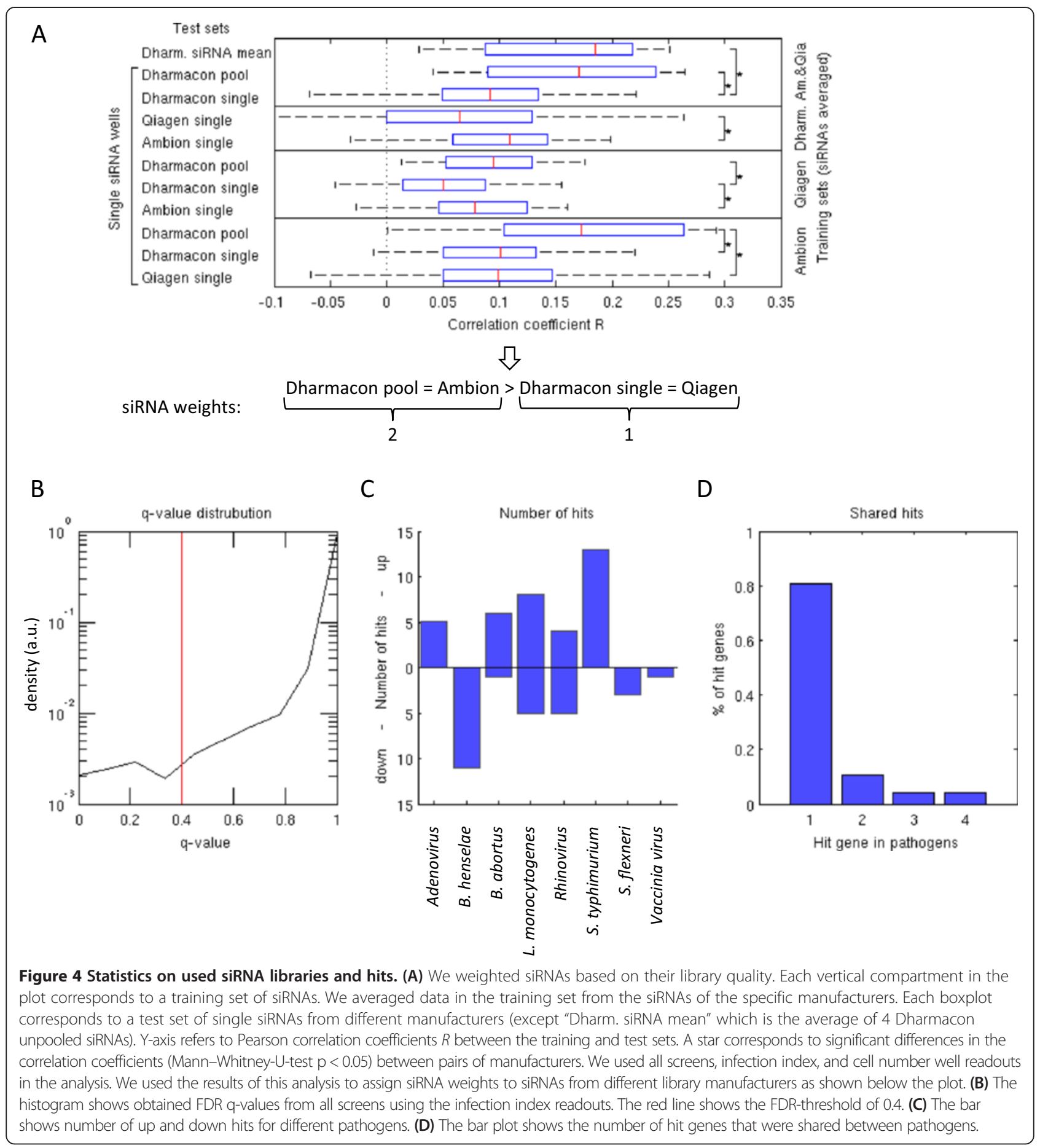

We cross-validated different libraries to each other by fixing one library manufacturer (training set) at a time (Figure 4A). We averaged phenotypic readouts from siRNAs targeting the same gene in the training set in order to obtain reference gene readouts. In this analysis we used both infection index and cell number readouts. We then compared single siRNA readouts of the remaining two library manufactures (test set) to the reference gene readouts. The Pearson correlation coefficients of the test sets enable to quantify which of the two test manufacturers produces more reproducible results. By repeating the procedure for all manufacturers as the training set we could order the manufacturers in terms of their reproducibility performance. Our results based on phenotypic readouts showed that the pooled Dharmacon library performed the best. The pooled library was 
followed by the unpooled libraries of Ambion, Dharmacon, and Qiagen in this order. However, there were no statistically significant differences (Wilcoxon rank-sum test $\mathrm{p}<0.05$ ) between Dharmacon pooled and Ambion single, and Dharmacon single and Qiagen single siRNA data reproducibility. In addition, the data showed that the averaged single siRNAs of Dharmacon performed at most as good as the single pooled siRNA consisting of the same siRNAs. This indicated that for most screening purposes, it is more practical to use the pooled library instead of several unpooled libraries. This result of better performance of pooled libraries compared to averaged single siRNA libraries is in contradiction with what has been reported in [19]. However, good quality single siRNA libraries (such as
A

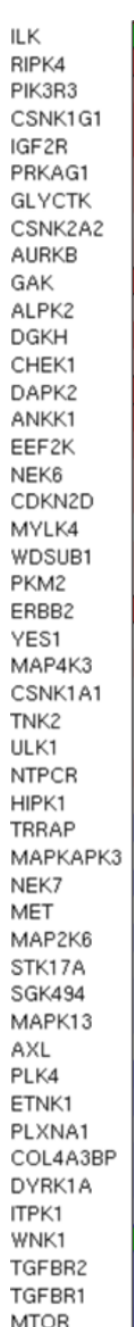

B
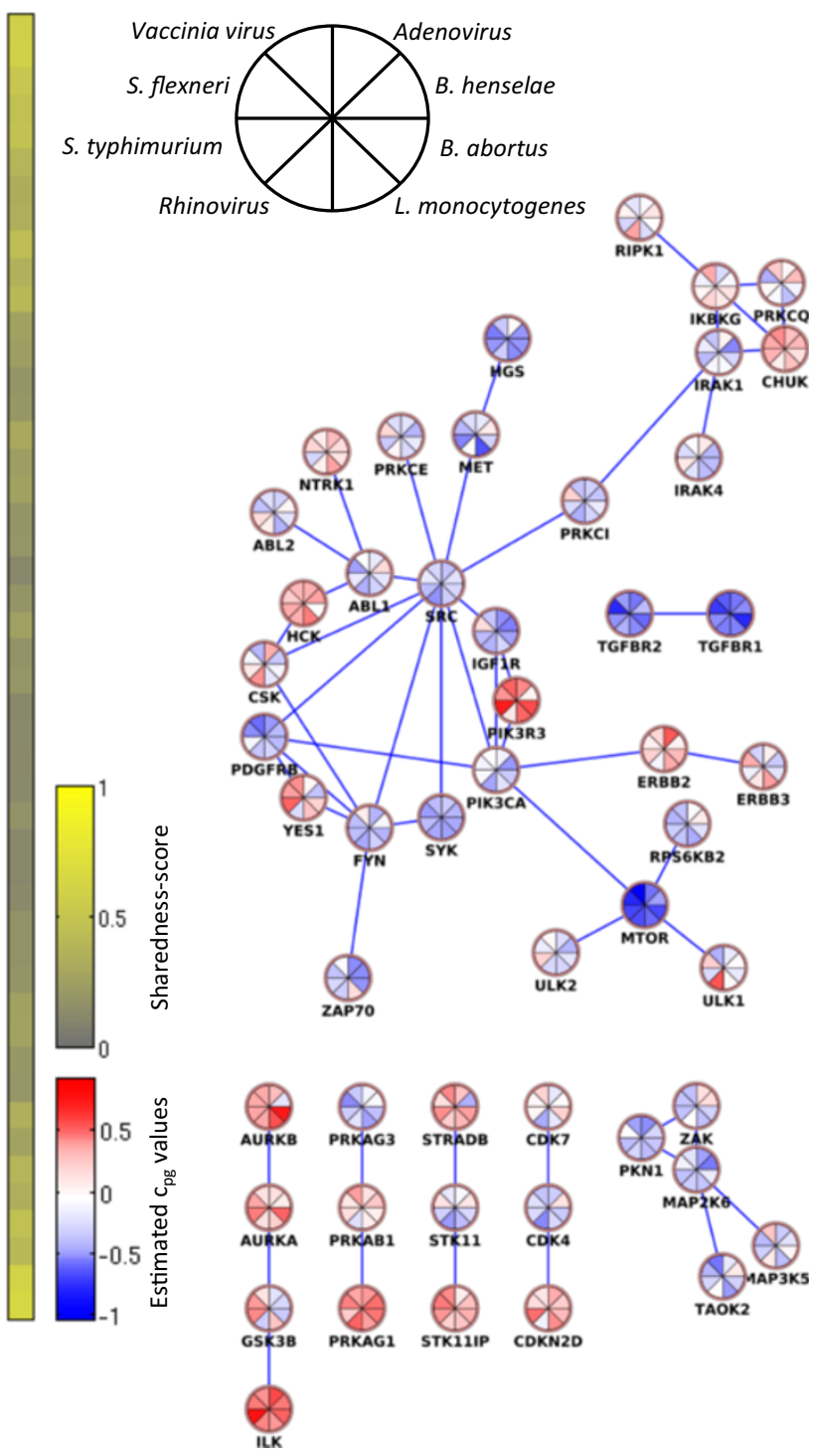

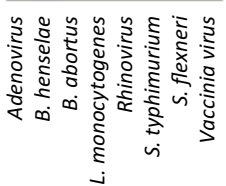

Figure 5 Summary of screening hits for all pathogens. (A) The heat map shows all genes which were significant (FDR $<0.4)$ at least for one pathogen. We ordered the genes by their averaged c-values over all pathogens. The colors correspond to the estimated c-values. The black outlines indicate significant hits (FDR $<0.4$ ) and the green outlines high-light the strongest down and up hits for each pathogen. The rightmost column shows the sharedness scores for each gene. (B) The network shows the hit genes (FDR $<0.4$ for at least one pathogen) and their direct neighbors that had connections between kinases in STRING database (version 9.0). The edges are functional interactions in the STRING database with edge threshold 850 . We removed genes that were not connected to any other gene from the network. Each node consists of a colored pie chart, in which each piece corresponds to a pathogen. 
Ambion Silencer Select) performed nearly as well as pooled libraries of less good single siRNAs (in our case Dharmacon SMARTpool). Following the results of the library analysis, we assigned a higher weight to Dharmacon Pooled and Ambion libraries (weight 2) than to the unpooled libraries Dharmacon and Qiagen (weight 1). PMM benefitted from the assigned library weights. The residual standard error of the linear mixed model reduced from 0.87 to 0.83 .

\section{Sharedness of detected significant genes}

By fitting PMM to our data, we found a left tailed local False Discovery Rate distribution, ending with a set of 50 different genes that reached the threshold of 0.4 (Figure 4B, Figure 5A). We selected threshold 0.4 as a reasonable hit threshold for this study since the difference was small compared to the set of hits with the commonly used threshold 0.2 and $40 \%$ false-positive rate was still acceptable in biological follow-up studies for us. The number of up and down hits varied between the pathogens (Figure 4C). Using FDR threshold $0.4,80 \%$ of hits were unique and $20 \%$ of hits were shared between two or more studied pathogens (Figure 4D). This provided a rough estimate that about $20 \%$ of genes gained statistical power from the parallel analysis using the PMM with our data. To quantify the hits according to their level of being shared between screens independently from the FDRthreshold, we developed the following "sharedness score" $s_{g}$ :

$$
s_{g}=\frac{1}{2}\left(\left(1-\operatorname{Mean}_{p}\left(q_{p g}\right)\right)+\frac{\sum_{p}\left(q_{p g}<1\right)}{P}\right) .
$$

Here $P$ is the total number of pathogens ( 8 in our case). The sharedness score is a combination of two quantities. The first part defines the shift away from 1 and the second part describes how many pathogens support this shift (proportion of $q_{p g}<1$ ). The score returns a value between 0 and 1 for each gene. Score 0 indicates that a gene is not shared among the pathogens and score 1 indicates that the gene is significant among all pathogens (Figure 5A). Since the sharedness score takes only the strength of a gene and not the directionality into account, a gene can be also highly shared if it inhibits in one pathogen and enhances the infection by another pathogen. Therefore, a gene shared between pathogens should be interpreted as being involved in the entry of these pathogens.

\section{Result comparison to existing hit ranking methods}

In order to validate the PMM approach and its results we compared it to other existing hit ranking methods and performed different kind of statistical tests. As reference methods we selected the Moderated T-Test (MTT) [36] and Redundant SiRNA Activity (RSA) [39] which are commonly used in high-throughput RNAi screening. We could not apply other widely used hit ranking methods, such as Strictly Standardized Mean Difference (SSMD) [40] or percent inhibition [29] since many of our pathogen screens did not have effective and reliable positive and negative control wells.

As a first test, we analyzed the stability of the obtained gene rankings with respect to the estimated $c_{p g}$ values $[30,41]$. We resampled with replacement 1000 datasets (12 siRNAs randomly selected with replacement for each gene) and calculated the number of genes that appear with high probability (prob $>0.9$ and prob $>0.7$ ) in the top of the ordered lists of genes based on their estimated $c_{p g}$ values (see Methods for details). This measure of stability showed similar results for PMM and the reference methods MTT and RSA (Figure 6A).

To mimic primary and validation screening setup and to study hit reproducibilities of the gene ranking methods we performed a leave-one-out cross-validation experiment. We used the siRNAs of unpooled libraries (11 in total) and left one siRNA set at a time away. We ran PMM, MTT, and RSA on the data sets consisting of 10 individual siRNAs and compared the resulting gene ranking to the ranked gene list of the remaining siRNA set. The averaged hit overlaps over all pathogens as a function of hit threshold $k$ are illustrated in Figure 6B. PMM performed the best indicating that the hits found by PMM are more reproducible by an independent siRNA screen than the hits found by the other methods.

In order to further estimate the hit-calling performance for different methods we performed data simulation with a-priori known hit structure. Data simulation was required since reliable ground truth hits are not generally available for the real biological systems. We simulated data by generating 1000 Gaussian distributed screens for each pathogen with four siRNAs. We selected four siRNAs since it makes up a realistic screening approach. We incorporated hits in each simulated screen by randomly selecting $10 \%$ of the genes and shifting them away from zero. We distinguished between three types of simulated data. In the first case the hits were different for each pathogen (unique hits only) and in the second case all hits were shared between the pathogens. The third case is probably the most realistic scenario containing both unique and shared hits to a varying degree (see Methods). We then applied PMM, MTT, and RSA to the simulated data and evaluated them by Receiver Operating Characteristic (ROC) -curves (with false positive versus true positive rates plotted for each FDR- threshold; Figure $6 \mathrm{C}-\mathrm{E}$ ). The results showed that PMM performed the best especially in the case of shared hits. For the case of unique hits PMM and MTT exhibited about the same performance while RSA performed the worst. As expected, with a higher shift of the hit genes the ROC curves got better for all methods. 


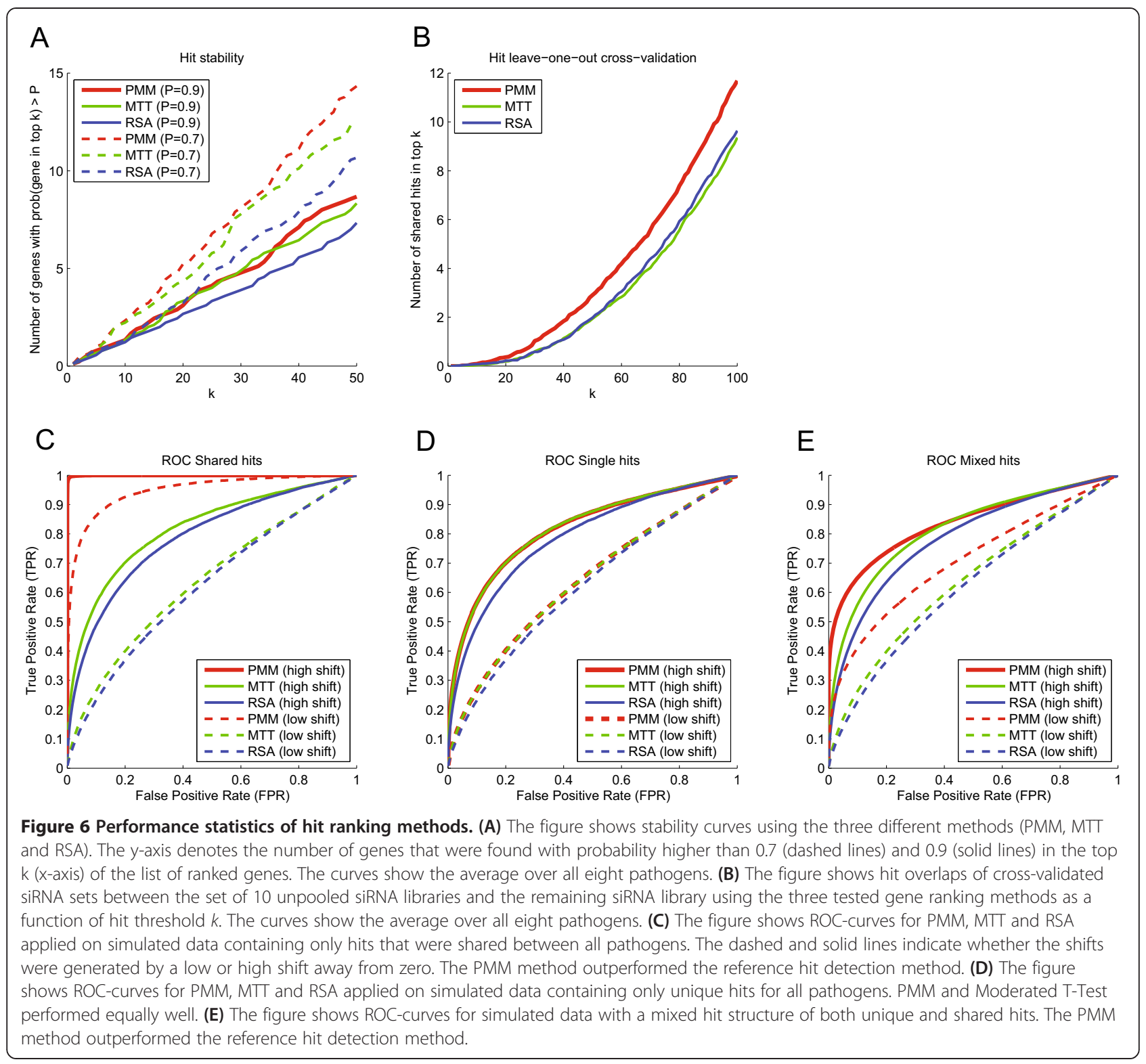

We also studied how simultaneous modeling affects the ranking of genes in individual screens using PMM. We performed a test where we selected a pathogen and created two datasets. The first dataset was the full data without any changes and the second dataset had the original data for the selected pathogen and randomized data for the 7 other pathogens. We then compared the gene rankings obtained by PMM performed using both datasets for the selected pathogen. The results for $L$. monocytogenes are illustrated in Figure 7A (see Additional file 1: Figure S6 for all the other pathogens). The correlation graph shows that the addition of parallel screens had only a mild effect on the overall gene ranking. However, when considering the number of significant genes (FDR $<0.4)$, PMM mainly added genes to the list of significant genes (7 novel significant genes for L. monocytogenes) and only few genes ( 1 for L. monocytogenes) were dropped off the list. In general, we concluded that using parallelism added novel significant genes while losing almost none. Moreover, the few lost hit genes had high FDR values, just slightly below the selected threshold FDR $<0.4$.

In the next step we analyzed the differences between the resulting gene rankings of the tested methods. Differences in gene rankings between PMM and other hit ranking methods were not very strong (see Figure 7B for MTT compared to PMM for L. monocytogenes and Additional file 1: Figure S7 for all other cases). Genes that had a high sharedness score and had an effect on the screen of interest (in particular MTOR and TGFBR1/2 for L. monocytogenes) gained statistical power from the simultaneous analysis and 

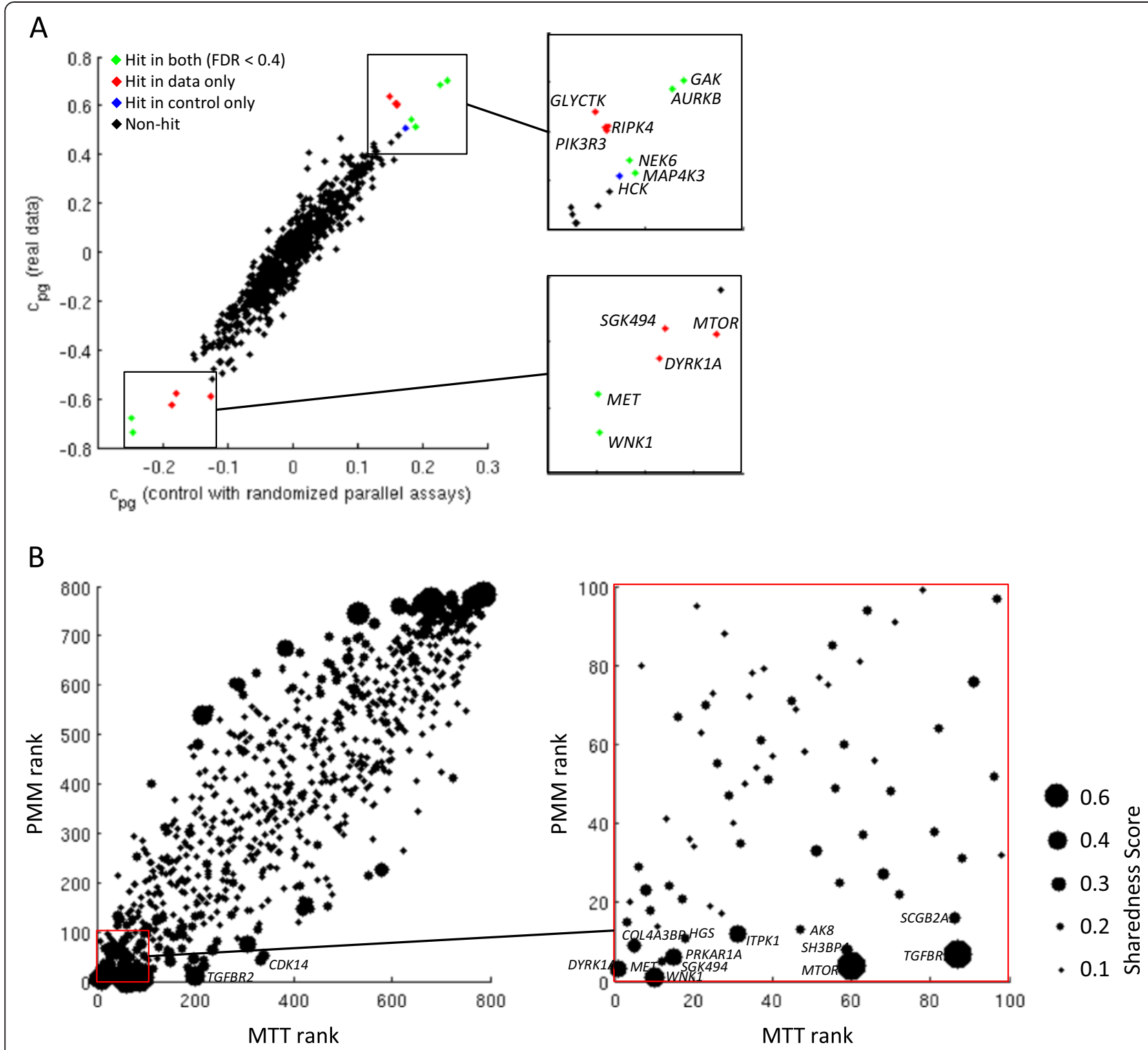

Figure 7 Summary of differences of PMM top hits compared to other hit scoring methods. (A) Y-axis shows the PMM gene ranking for $L$. monocytogenes. X-axis is the same, but we randomized the other 7 parallel assays. The colors correspond to hit genes (FDR $<0.4)$ in different cases. Parallelism yielded only a slight effect on the ranking, but added genes to the list of significant hit genes. (B) The scatter plot shows PMM hit ranking (y-axis) compared to the MTT hit ranking ( $\mathrm{x}$-axis) for $\mathrm{L}$. monocytogenes. The dot size corresponds to the sharedness score of each gene. Some genes with high sharedness scores gained statistical power.

were pushed up in the gene ranking. On the other hand, we observed that PMM detected several genes with low sharedness scores, indicating that unique hits were not neglected.

In order to evaluate the biological relevance of observed hits, we calculated pathway enrichment scores separately for each pathogen by the Gene Set Enrichment Analysis (GSEA) algorithm [42] using as input the results from the three hit ranking algorithms PMM, MTT, and RSA (see Additional file 1). We selected all pathways that were significant (GSEA pathway enrichment FDR score $<0.2$ ) for at least one pathogen and method pair. We used the ranking of infection indices as the input for GSEA and focused on hits that reduce infection levels. By assuming that most pathways in the used database are biologically valid, we would expect that better hit detection methods give a higher number of enriched pathways than less powerful hit detection methods. However, we only screened kinases and the applicable pathways are limited to those that are highly enriched in phosphorylation events and it may be that some pathogens do not show strong enrichments within this set of pathways. Moreover, differences in pathway 
enrichments between methods may have occurred because they treated missing values differently. Therefore, the enrichment results should be evaluated with caution. Additional file 1: Figure S9 illustrates the observed significant pathways. The number of enriched (GSEA FDR $<0.2)$ pathways for each method was an indication that PMM detected biologically more relevant hit genes than the other methods.

\section{Biological inquiry on detected significant genes}

The performed screens yield several interesting hits of which most are novel to the corresponding pathogen (Figure 5A, see Additional file 1: Figure S10 for cell number hits). Many of the strongest hits, including $M T O R, T G F B R 1 / 2$ for negative hits and $I L K$ for positive hits, were shared between most of the studied pathogens. This was also illustrated by the sharedness scores of detected hit genes. Many of the strongest shared hits were related to $S R C, M T O R$, or $C D K$ related pathways. Although SRC and CDK4 were not part of the hit lists $\left(q_{p g}<0.4\right)$ for any of the pathogens, they exhibited consistent semi-strong effect for most pathogens. A network analysis of hit genes showed that several of the shared hits can be described as "network hubs" that are involved in many cellular processes and highly connected to other genes (including MTOR and $S R C$ ) (Figure 5B) [43]. MTOR is a mammalian target of rapamycin, serine/ threonine protein kinase that regulates cell growth, cell proliferation, cell motility, cell survival, protein synthesis, and transcription. The involvement of MTOR in Adenovirus, Poliovirus, Enterovirus71, Coxackievirus, Vaccinia virus and other pathogens has already been established $[6,9,15]$. Our data also reproduced the established role of MTOR during S. typhimurium infections, since S. typhimurium depends on a reactivation of MTOR during its course of infection in order to escape autophagy [38]. Interestingly, TGFBR1 and TGFBR2 came up both as strong hits for many pathogens. TGFBR1 and TGFBR2 proteins must heterodimerize to form a functional TGFbeta receptor at the plasma membrane. Their similar strong infection reducing knock-down phenotypes, seen in most independent pathogen screens, indicated the validity of these hits and suggested a broad, yet poorly understood, function of this membrane protein for various pathogens. In particular, there are suggestions [44] that the TGFB pathway might be important for B. abortus infection since in chronic brucellosis patients there is increased TGF beta production and this could aid infection by depressing lymphocyte functions. In addition, our study confirmed the role of DYRK family members (in particular $D Y R K 1 A)$ as they have been identified to be general regulators for several viruses in Snijder, Sacher et al. [9].

Despite the overall similarity of infection patterns between pathogens, most pathogens also contained hits that were specific for the pathogen (for example $M E T$ for $L$. monocytogenes, NTPCR for B. henselae, and ETNK1 and ULK1 for Rhinovirus). Some of the hit genes have previously been found to be effectors, for example $M E T$ for $L$. monocytogenes. L. monocytogenes enters host cells by triggering signaling cascades activated through interaction of bacterial internalin $A(\operatorname{Inl} A)$ or $\operatorname{InlB}$ with the adherens junction protein $E$-cadherin or the hepatocyte growth factor receptor MET [37] respectively. Since E-cadherin is not expressed in HeLa cells, which were used for our siRNA screens, the $I N L B$ / MET pathway is the only route of entry in this cellular system. In fact, $M E T$ [45] was one of the strongest hits for L. monocytogenes. The exact roles of most hit genes of all pathogens are largely unknown, but several hit genes create interesting hypotheses for follow-up. For example, it was proposed based on microRNA analysis of infected macrophages, that AMPK might be a target gene that promotes intracellular survival during B. abortus infection [46]. PIK3R3 (p55-gamma; Phosphatidylinositol 3-Kinase $55 \mathrm{KD}$ a Regulatory Subunit Gamma) a semi-strong hit for several pathogens in our data was identified as a hit in an RNAi screen of drosophila S2 cells, in agreement with the importance of PI3K during $B$. abortus infection [47]. PIK3CA probably plays a role also in $B$. henselae infection through actin modulation. PIK3CA levels influence RHOA and $R A C 1$, which are involved in actin dynamics [48]. Furthermore, PIK3CA is involved in PIP3 production, which is a signaling molecule and has recently been shown to be related to the formation of dynamic F-actin-related structures [49]. ULK1 (unc-51 like autophagy activating kinase 1) plays an important role in autophagy as well as Hepatitis $C$ virus infection. Therefore, ULK1 has a possible link to Rhinovirus induced autophagy. COLAABBP is possibly linked to Rhinovirus entry through ceramide-enriched membrane platforms [50] since COL4A3BP specifically phosphorylates the $\mathrm{N}$-terminal region of the non-collagenous domain of the alpha 3 chain of type IV collagen, known as the Goodpasture antigen, also involved in ceramide intracellular transport (from ER to Golgi).

\section{Conclusions}

We produced a uniquely wide high-content siRNA dataset, in terms of used siRNA libraries (11 single siRNAs and one pool) and eight different pathogens. Our highly unified protocols and common image analysis as well as similar data analysis pipelines enabled a direct comparison between the phenotypic readouts of the different pathogen screens. The unified structures of the datasets also aided discovering shared mechanisms between the studied pathogens.

Using our novel statistical approach PMM we detected several interesting and new hits from our kinome-wide pathogen screens. The hits will require further follow-up 
work in order to understand the exact biological mechanisms of the genes. In addition, we discovered shared effector genes between the studied pathogens including MTOR, TGFBR1 and TGFBR2 that were strong hits for almost all studied pathogens. In particular, the obtained sharedness scores indicated whether a hit gene has a very specific function for a single pathogen or a more generic cellular function that is shared between many pathogens and thus gave us the first indications of the gene's roles. Pharmaceutically oriented follow-up studies could take advantage of this concept. For example, if we were interested in general regulators we could focus on genes with high sharedness scores. On the other hand, regulators that have a very specific effect and a low sharedness score could probably have fewer side effects.

We showed that the reliability of hit scoring in individual RNAi screens improved by using PMM that takes advantages of the parallelism in RNAi screening. PMM can, in principle, be applied to any kind of parallel RNAi screens almost independently of the underlying biology or field of application as long as the readouts of the screens are measured on the same scale. We can often obtain this by applying Z-Scoring or similar normalization methods to the well readouts. The difference to other approaches aiming at the comparison of independent parallel RNAi screens is that PMM takes simultaneously all screening data into account. For example, for the comparison of insect and human data in [51] the hit lists were derived by separate statistics on each screen. By taking all data into the analysis the statistical power can be increased. Based on our results, we expect that the more similar the parallel screens are in the sense of biological focus or protocols, the more statistical power can be gained from the simultaneous analysis. Even a slight overlap between the underlying biological pathways of the parallel screens can improve the hit detection in individual screens without compromising the detection of unique hits for any individual screens. Provided that the large-scale RNAi screening community reaches standardized data publication and sharing standards through projects such as MIARE and GenomeRNAi, the PMM approach could be expanded to include the vast number of different RNAi screens performed in different laboratories worldwide that used the same siRNA libraries. In principle and as a vision, this opens up great opportunities for simultaneous statistical approaches such as PMM. Every new screen could potentially gain statistical power by using the public resources. In addition, PMM can potentially be used to gain power for secondary validation screens. Such validation screens are typically performed with several independent siRNAs targeting the same gene under various conditions and PMM would be directly applicable. A beneficial feature of PMM is the possibility to assign weights to the siRNAs. The weights can incorporate a-priori information about the performance of individual siRNAs and their phenotypical readout. This concept of weighting can be expanded over what we presented in this paper. In particular, statistical and bioinformatics analyses on seed sequence induced off-target effects could potentially be used as basis for weights. Naturally any additional high-throughput data, such as proteomics analyses on cells under siRNA perturbations, or genomic analyses on specific cell lines, could be used to assign realistic siRNA weights to improve hit scoring.

We aimed to take a step forward in determining minimal requirements for image-based RNAi screening data publication. All the raw images, library metadata, single cell measurements, and well measurements are publicly available through our openBIS based publication portal. In addition, we provide easy-to-access data aggregates in standardized tabular formats with all the necessary metadata information. Our uniquely wide datasets provide a large resource for infection biologists, image analysts, and statisticians for future research.

\section{Methods \\ Wet-lab protocols \\ Cell culturing conditions}

HeLa CCL-2 (ATCC) cells were maintained at $37^{\circ} \mathrm{C}$ and $5 \% \mathrm{CO}_{2}$ in Dulbecco Modified Eagle Medium (DMEM, Invitrogen) supplemented with $10 \%$ inactivated FCS (Invitrogen).

\section{siRNA reverse transfection}

RNA interference directed against human kinases and kinase-associated genes (826 genes in total) was achieved using commercially available siRNA libraries. All experiments were conducted in a 384-well plate format. In addition to screening plates, control plates were included in each screen. All plates contained general siRNA controls for transfection efficiency and toxicity (e.g. Kif11), as well as, control siRNAs for infection effects of each pathogen assayed. However, for most of the pathogens in this study, reliable and well established positive control siRNAs (reducing or enhancing infection levels) were not available prior to screening. In addition, negative controls such as MOCK (no siRNA) and SCRAM$B L E D$ (non-targeting siRNA) were added to every plate.

In each experiment, $25 \mu \mathrm{l}$ of RNAiMAX/DMEM $(0.1 \mu \mathrm{l} /$ $24.9 \mu \mathrm{l})$ mixture was added to each well of the screening plates containing 1.6 pmol siRNA diluted in $5 \mu \mathrm{l}$ RNasefree $\mathrm{dd}_{2} \mathrm{O}$. Screening plates were thereafter incubated at room temperature (RT) for $1 \mathrm{~h}$. Following incubation, a pathogen assay-specific number of HeLa CCL-2 cells (see Additional file 1: Table S1) were added per well in a volume of $50 \mu \mathrm{l}$ DMEM/16\% FCS, resulting in a final FCS concentration of 10\% (Adenovirus screens contained 6.7\% 
final FCS). Plates were incubated at $37^{\circ} \mathrm{C}$ and $5 \% \mathrm{CO}_{2}$ for $72 \mathrm{~h}$ prior to infection.

\section{Fixation and staining}

After infection cells were fixed using paraformaldehyde (PFA). Cells were stained for DNA, F-actin and infection specific markers. Screening plates were sealed prior to imaging.

\section{Adenovirus-specific protocol}

All liquid handling stages of infection, fixation, and immunofluorescence staining were performed on the automated pipetting system Well Mate (Thermo Scientific Matrix) and washer Hydrospeed (Tecan). For infection screens recombinant Ad2_ $\triangle \mathrm{E} 3 \mathrm{~B}$-eGFP (short Adenovirus) was utilized as described before [52,53]. Adenovirus was added to cells at a multiplicity of infection (moi) of 0.1 in $10 \mu \mathrm{l}$ of an infection media/FBS (DMEM supplemented with L-glutamine, 10\% FBS, 1\% Pen/Strep, Invitrogen). Screening plates were incubated at $37^{\circ} \mathrm{C}$ for $16 \mathrm{~h}$, and cells were fixed by adding $21 \mu \mathrm{l}$ of $16 \%$ PFA directly to the cells in culture media for $45 \mathrm{~min}$ at RT or long-term storage at $4^{\circ} \mathrm{C}$. Cells were washed 2 times with $\mathrm{PBS} / 25 \mathrm{mM} \mathrm{NH}_{4} \mathrm{Cl}$, permeabilized with $25 \mu \mathrm{l} 0.1 \%$ Triton X-100 (Pharmaciebiothek). After 2 washes with PBS the samples were incubated at RT for $1 \mathrm{~h}$ with $25 \mu \mathrm{l}$ staining solution (PBS) containing DAPI $(1 \mu \mathrm{g} / \mathrm{ml}$, Sigma-Aldrich) and DY-647phalloidin (1 U/ml, Dyomics),washed 2 times with PBS and stored until imaging in $50 \mu \mathrm{PBS} / \mathrm{NaN}_{3}$.

\section{Bartonella henselae -specific protocol}

Bacterial strain SEB0109: Bartonella henselae ATCC49882 ${ }^{\mathrm{T}}$ $\triangle$ bepG containing plasmid pCD353 [54] for IPTGinducible expression of GFP. Culturing conditions: bacteria were grown on Columbia base agar (CBA) plates supplemented with $5 \%$ defibrinated sheep blood (Oxoid) and $50 \mu \mathrm{g} / \mathrm{ml}$ kanamycin. Bacteria were incubated at $35^{\circ} \mathrm{C}$ in $5 \% \mathrm{CO}_{2}$ for $72 \mathrm{~h}$ before re-streaking them on fresh $\mathrm{CBA}$ and further growth for $48 \mathrm{~h}$. Infection: siRNAtransfected cells were washed once with M199 (Invitrogen) $/ 10 \%$ FCS using a plate washer (ELx50-16, BioTek). Cells were infected with $B$. henselae at an MOI of 400 in $50 \mu \mathrm{l}$ of M199/10\% FCS and 0.5 mM IPTG (Applichem) and were incubated at $35^{\circ} \mathrm{C}$ in $5 \% \mathrm{CO}_{2}$ for $30 \mathrm{~h}$. Fixation at RT: using a Multidrop 384 (Thermo Scientific) cells were washed with $50 \mu \mathrm{l}$ of PBS, fixed in $20 \mu \mathrm{l}$ of $3.7 \%$ PFA for $10 \mathrm{~min}$, and washed once more with $50 \mu \mathrm{l}$ of PBS. Staining on a Biomek liquid handling platform: fixed cells were washed twice with $25 \mu \mathrm{l}$ of PBS and blocked in PBS/ $0.2 \%$ BSA for $10 \mathrm{~min}$. Extracellular bacteria were labeled with a rabbit serum 2037 against $B$. henselae [23] and a secondary antibody goat anti rabbit Alexa Fluor 647 (Jackson Immuno) in PBS/0.2\% BSA. Antibodies were incubated for $30 \mathrm{~min}$ each and both incubations were followed by two washings with $25 \mu \mathrm{l}$ of PBS. Cells were then permeabilized with $20 \mu \mathrm{l}$ of $0.1 \%$ Triton X-100 (Sigma) for $10 \mathrm{~min}$ and afterwards washed twice with $25 \mu \mathrm{l}$ of PBS, followed by the addition of $20 \mu \mathrm{l}$ of staining solution (PBS containing 1.5 U/ml DY-547-Phalloidin (Dyomics) and $1 \mathrm{ug} / \mathrm{ml}$ DAPI (Roche)). After $30 \mathrm{~min}$ of incubation in the staining solution, cells were washed twice with $25 \mu \mathrm{l}$ PBS, followed by a final addition of $50 \mu \mathrm{l}$ of PBS.

\section{Brucella abortus -specific protocol}

Brucella abortus 2308 pJC43 (aphT::GFP) [55] were grown in tryptic soy broth (TSB) medium containing $50 \mu \mathrm{g} / \mathrm{ml}$ kanamycin for $20 \mathrm{~h}$ at $37^{\circ} \mathrm{C}$ and shaking (100 rpm) to an OD of 0.8-1.1. $50 \mu \mathrm{l}$ of DMEM/10\% containing bacteria was added per well to obtain a final moi of 10000 using a cell plate washer (ELx50-16, BioTek). Plates were then centrifuged at $400 \mathrm{~g}$ for $20 \mathrm{~min}$ at $4^{\circ} \mathrm{C}$ to synchronize bacterial entry. After $4 \mathrm{~h}$ incubation at $37^{\circ} \mathrm{C}$ and $5 \% \mathrm{CO}_{2}$, extracellular bacteria were killed by exchanging the infection medium by $50 \mu \mathrm{l}$ medium supplemented with $10 \%$ FCS and $100 \mu \mathrm{g} / \mathrm{ml}$ gentamicin (Sigma). After a total infection time of $44 \mathrm{~h}$ cells were fixed with $3.7 \%$ PFA for $20 \mathrm{~min}$ at RT with the cell plate washer. Staining was performed using a Biomek liquid handling platform. Cells were washed twice with PBS and permeabilized with $0.1 \%$ Triton X (Sigma) for $10 \mathrm{~min}$. Then, cells were washed twice with PBS, followed by addition of $20 \mu \mathrm{l}$ of staining solution which includes DAPI $(1 \mu \mathrm{g} / \mathrm{ml}$, Roche) and DY547-phalloidin (1.5 U/ml, Dyomics) in 0.5\% BSA in PBS. Cells were incubated with staining solution for $30 \mathrm{~min}$ at $\mathrm{RT}$, washed twice with PBS, followed by final addition of $50 \mu \mathrm{l}$ PBS.

\section{Listeria monocytogenes -specific protocol}

After washing an overnight culture of L. monocytogenes EGDe.PrfA*GFP three times with PBS, bacteria were diluted in DMEM supplemented with 1\% FCS. Cells were infected at a moi of 25 in $30 \mu \mathrm{l}$ infection medium per well. After centrifugation at $1000 \mathrm{rpm}$ for $5 \mathrm{~min}$ and incubation for $1 \mathrm{~h}$ at $37^{\circ} \mathrm{C}$ in $5 \% \mathrm{CO}_{2}$ to allow the bacteria to enter, extracellular bacteria were killed by exchanging the infection medium by $30 \mu$ DMEM supplemented with $10 \%$ FCS and $40 \mu \mathrm{g} / \mathrm{ml}$ gentamicin (Gibco). Both medium exchange steps were carried out with a plate washer (ELx50-16, BioTek). After additional $4 \mathrm{~h}$ at $37^{\circ} \mathrm{C}$ in a $5 \% \mathrm{CO}_{2}$ atmosphere, cells were fixed for $15 \mathrm{~min}$ at RT by adding $30 \mu \mathrm{l}$ of $8 \%$ PFA in PBS to each well using a multidrop 384 device (Thermo Electron Corporation). PFA was removed by four washes with $500 \mu \mathrm{l}$ PBS per well using the Power Washer 384 (Tecan). Fixed cells were stained for nuclei, actin and bacterially secreted InlC. First, cells were incubated for $30 \mathrm{~min}$ with $10 \mu \mathrm{l} /$ well of primary staining solution $(0.2 \%$ saponin, $\mathrm{PBS})$ containing 
rabbit derived anti-InlC serum (1:250). After four washes with $40 \mu \mathrm{l}$ PBS per well cells were stained with $10 \mu \mathrm{l} /$ well of the secondary staining solution ( $0.2 \%$ saponin, PBS) containing Alexa Fluor-546 coupled anti-rabbit antibody (1:250, Invitrogen), DAPI (0.7 $\mu \mathrm{g} / \mathrm{ml}$, Roche), and DY-647Phalloidin (2 U/ml, Dyomics). After four washes with $40 \mu \mathrm{l}$ PBS per well, the cells were kept in $40 \mu \mathrm{l}$ PBS per well. The staining procedure was carried out with a Tecan freedom evo robot.

\section{Rhinovirus-specific protocol}

All liquid handling stages of infection, fixation, and immunofluorescence staining were performed on the automated pipetting system Well Mate (Thermo Scientific Matrix) and washer Hydrospeed (Tecan). For infection assays with human Rhinovirus serotype 1a (HRV1a) were carried out as described, except that the anti-VP2 antibody Mab 16/7 was used for staining of the infected cells as described earlier [56-58]. Rhinovirus at a moi of 8 was added to cells in $20 \mu \mathrm{l}$ of an infection media/BSA (DMEM supplemented with GlutaMAX, $30 \mathrm{mM} \mathrm{MgCl}$ and $0.2 \%$ BSA, Invitrogen). Screening plates were incubated for $7 \mathrm{~h}$ at $37^{\circ} \mathrm{C}$, and cells were fixed by adding $33 \mu \mathrm{l}$ of $16 \%$ PFA directly to the culture medium. Fixation was either for $30 \mathrm{~min}$ at $\mathrm{RT}$ or long term storage at $4^{\circ} \mathrm{C}$. Cells were washed twice with $\mathrm{PBS} / 25 \mathrm{mM} \mathrm{NH} \mathrm{m}_{4} \mathrm{Cl}$, permeabilized with $50 \mu \mathrm{l} 0.2 \%$ Triton X-100 (Sigma-Aldrich) followed by 3 PBS washes and blocking with PBS containing 1\% BSA (Fraction V, Sigma-Aldrich). Fixed and permeabilized cells were incubated at RT for $1 \mathrm{~h}$ with diluted mabR16-7 antibody $(0.45 \mu \mathrm{g} / \mathrm{ml})$ in PBS/1\% BSA. Cells were washed 3 times with PBS and incubated with $25 \mu \mathrm{l}$ secondary staining solution (PBS/1\% BSA) containing Alexa Fluor 488 secondary antibody $(1 \mu \mathrm{g} / \mathrm{ml}$, Invitrogen $)$, DAPI $(1 \mu \mathrm{g} / \mathrm{ml}$, Sigma-Aldrich), and DY-647-phalloidin $(0.2 \mathrm{U} / \mathrm{ml}$, Dyomics). Cells were washed twice with PBS after $2 \mathrm{~h}$ of incubation in secondary staining solution and stored in $50 \mu \mathrm{lBS} / \mathrm{NaN}_{3}$.

\section{Salmonella typhimurium -specific protocol}

All liquid handing stages of infection, fixation, and immunofluorescence staining were performed on a liquid handling robot (BioTek; EL406). For infection the $S$. typhimurium strain S.Tm ${ }^{\text {SopE_pM975 }}$ was used. This strain is a single effector strain, only expressing SopE out of the main four SPI-1 encoded effectors (SipA, SopB, SopE2 and SopE). Additionally this strain harbors a plasmid (pM975) that expresses GFP under the control of a SPI2 (ssaG)-dependent promoter. The bacterial solution was prepared by cultivating a $12 \mathrm{~h}$ culture in $0.3 \mathrm{M} \mathrm{LB}$ medium containing $50 \mu \mathrm{g} / \mathrm{ml}$ streptomycin and $50 \mu \mathrm{g} /$ $\mathrm{ml}$ ampicillin. Afterwards a $4 \mathrm{~h}$ subculture (1:20 diluted from the $12 \mathrm{~h}$ culture) was cultivated in $0.3 \mathrm{M} \mathrm{LB}$ medium containing $50 \mu \mathrm{g} / \mathrm{ml}$ streptomycin, which reached an $\mathrm{OD}_{600 \mathrm{~nm}} \approx 1.0$ after the respective $4 \mathrm{~h}$ of incubation time. To perform the infection, $16 \mu$ l of diluted S. typhimurium $(\mathrm{moi}=80)$ were added to the HeLa cells. After $20 \mathrm{~min}$ of incubation at $37^{\circ} \mathrm{C}$ and $5 \% \mathrm{CO}_{2}$, the $S$. typhimurium-containing media was replaced by $60 \mu \mathrm{l}$ DMEM/10\% FCS containing $50 \mu \mathrm{g} / \mu \mathrm{l}$ streptomycin and $400 \mu \mathrm{g} / \mu \mathrm{l}$ gentamicin to kill all remaining extracellular bacteria. After additional $3 \mathrm{~h} 40 \mathrm{~min}$ incubation at $37^{\circ} \mathrm{C}$ and $5 \% \mathrm{CO}_{2}$, cells were fixed by adding $35 \mu \mathrm{l} 4 \%$ PFA, $4 \%$ sucrose in PBS for $20 \mathrm{~min}$ at RT. The fixation solution was removed by adding $60 \mu \mathrm{l}$ PBS containing $400 \mu \mathrm{g} / \mathrm{ml}$ gentamicin. Cells were permeabilized for $5 \mathrm{~min}$ with $40 \mu \mathrm{l}$ $0.1 \%$ Triton X-100 (Sigma-Aldrich). Afterwards $24 \mu \mathrm{l}$ of staining solution containing DAPI (1:1000, Sigma-Aldrich) and DY-547-phalloidin (1.2 U/ml, Dyomics) was added (prepared in blocking buffer consisting of 4\% BSA and 4\% Sucrose in PBS). After $1 \mathrm{~h}$ of incubation at RT, cells were washed three times with PBS followed by the addition of $60 \mu \mathrm{l}$ PBS containing $400 \mu \mathrm{g} / \mathrm{ml}$ gentamicin.

\section{Shigella flexneri -specific protocol}

S. flexneri M90T $\Delta$ virG pCK100 (PuhpT::dsRed) were harvested in exponential growth phase and coated with $0.005 \%$ poly-L-lysine (Sigma-Aldrich). Afterwards, bacteria were washed with PBS and resuspended in assay medium (DMEM, $2 \mathrm{mM}$ L-Glutamine, $10 \mathrm{mM}$ HEPES). $20 \mu \mathrm{l}$ of bacterial suspension was added to each well with a final moi of 15 . Plates were then centrifuged for $1 \mathrm{~min}$ at $37^{\circ} \mathrm{C}$ and incubated at $37^{\circ} \mathrm{C}$ and $5 \% \mathrm{CO}_{2}$. After $30 \mathrm{~min}$ of infection, $75 \mu \mathrm{l}$ were aspirated from each well and monensin (Sigma) and gentamicin (Gibco) were added to a final concentration of $66.7 \mu \mathrm{M}$ and $66.7 \mu \mathrm{g} / \mathrm{ml}$, respectively. After a total infection time of $3.5 \mathrm{~h}$, cells were fixed in $4 \%$ PFA for $10 \mathrm{~min}$. Liquid handling was performed using the Multidrop 384 (Thermo Scientific) for dispension steps and a plate washer (ELx50-16, BioTek) for aspiration steps. For immunofluorescent staining, cells were washed with PBS using the Power Washer 384 (Tecan). Subsequently, cells were incubated with a mouse anti-human IL-8 antibody (1:300, BD Biosciences) in staining solution ( $0.2 \%$ saponin in PBS) for $2 \mathrm{~h}$ at RT. After washing the cells with PBS, Hoechst (5 $\mu \mathrm{g} / \mathrm{ml}$, Invitrogen), DY-495-phalloidin (1.2 $\mathrm{U} / \mathrm{ml}$, Dyomics) and Alexa Fluor 647-coupled goat anti-mouse IgG (1:400, Invitrogen) were added and incubated for $1 \mathrm{~h}$ at RT. The staining procedure was performed using the Biomek NXP Laboratory Automation Workstation (Beckman Coulter).

\section{Vaccinia virus-specific protocol}

All liquid handing stages of infection, fixation, and immunofluorescence staining were performed on a liquid handling robot (BioTek, EL406). For infection assays a recombinant WR VACV, WR E EGFP/L mCherry, was utilized. For infection, media was aspirated from the 
RNAi-transfected cell plates and replaced with $40 \mu \mathrm{l}$ of virus solution per well $(\mathrm{moi}=0.125)$. Screening plates were incubated for $1 \mathrm{~h}$ at $37^{\circ} \mathrm{C}$ to allow for infection, after which virus-containing media was removed and replaced with $40 \mu \mathrm{l}$ DMEM/10\% FCS. $8 \mathrm{~h}$ after infection $40 \mu \mathrm{l}$ of DMEM/10\%FCS containing $20 \mu \mathrm{M}$ cytosine arabinoside (AraC) was added to all wells to prevent virus DNA replication in secondary infected cells. $24 \mathrm{~h}$ after infection cells were fixed by the addition of $20 \mu \mathrm{l} 18 \%$ PFA for $30 \mathrm{~min}$ followed by two PBS washes of $80 \mu \mathrm{l}$. For immunofluorescence staining of EGFP, cells were incubated for $2 \mathrm{~h}$ in $30 \mu \mathrm{l}$ primary staining solution $(0.5 \%$ Triton X-100, 0.5\% BSA, PBS) per well, containing antiGFP antibody (1:1000). Cells were washed twice in $80 \mu \mathrm{l}$ PBS, followed by the addition of $30 \mu$ l secondary staining solution (0.5\% BSA, PBS) containing Alexa Fluor 488 secondary antibody (1:1000), Hoechst (1:10000), and DY-647-phalloidin (1:1200, Dyomics). Cells were washed twice with $80 \mu \mathrm{l}$ PBS after $1 \mathrm{~h}$ incubation in secondary staining solution followed by the addition of $80 \mu \mathrm{l} \mathrm{H}_{2} \mathrm{O}$.

\section{Microscopy}

Microscopy was performed with Molecular Devices ImageXpress microscopes. We used the MetaXpress plate acquisition wizard with no gain, 12 bit dynamic range, 9 sites per well in a $3 \times 3$ grid with no spacing and no overlap and laser-based focusing. Channels were assay specific (see Additional file 1: Table S2). Robotic plate handling was used to load and unload plates (Thermo Scientific). The objective was a 10X S Fluor with 0.45 NA. The Site Autofocus was set to "All Sites" and the initial well for finding the sample was set to "First well acquired". ZOffset for Focus was selected manually and "AutoExpose" was used to get a good exposure time. Manual correction of the exposure time was applied to ensure a wide dynamic range with low overexposure, when necessary.

\section{Statistical analyses \\ Image analysis and data normalization}

Image analysis and data normalization was based on modified CellProfiler [28] workflows. Please refer to Additional file 1 for detailed description of computational infrastructure, image analysis, and data normalization.

\section{Parallel Mixed Model (PMM)}

We denote the readout of siRNA $s$ silencing gene $g$ for a pathogen $g$ as $y_{p g s}$. The linear mixed model of PMM is defined as the following linear model

$$
\begin{aligned}
& y_{p g s}=\mu_{p}+a_{g}+b_{p g}+\varepsilon_{p g s}, \\
& a_{g} \sim N\left(0, \sigma_{a}^{2}\right), b_{p g} \sim N\left(0, \sigma_{b}^{2}\right), \varepsilon_{p g s} \sim N\left(0, \sigma_{\varepsilon}^{2}\right),
\end{aligned}
$$

where $\mu_{p}$ is the fixed effect for pathogen $p$ (typically close to 0 because of data Z-Scoring), $a_{g}$ is the gene effect overall pathogens, $b_{p g}$ is the gene effect within a pathogen and $\varepsilon_{p g s}$ denotes the error term. The parameters are estimated by maximizing the restricted maximum likelihood using the Newton-Raphson algorithm [33]. We used the implemented version in the "lmer" function from the "lme4" R-package [34]. This implementation allows also the use of weights, which are incorporated by a weighted maximum likelihood formulation. The weights are constant values where each constant corresponds to exactly one data point. For our data, each weight is associated with a single readout of an independent siRNA. The size of the weight indicates the precision of the information contained in the associated readout. The assumptions of the linear mixed model are fulfilled (see Additional file 1: Figure S11).

\section{Local false discovery rate (q) estimation in PMM}

The observed distribution of the estimated $c_{p g}$ is a mixture of the null $f_{O}$ and the non-null distribution $f_{l}$. The null distribution describes the distribution of all genes that are no-hits. The non-null distribution corresponds to the genes that are hits, having either a positive or negative effect. The two distributions are assumed to differ only in the mean. The non-null distribution is shifted by a factor $\Theta$ away from zero. With this we define the local false discovery rate as

$$
\begin{aligned}
& f d r(c)=P(\text { No Hit } \mid c)=\frac{\pi_{0} f_{0}(c)}{f(c)} \\
& f_{0} \sim N\left(0, \sigma_{a}^{2}+\sigma_{b}^{2}\right), f_{1} \sim N\left(\theta, \sigma_{a}^{2}+\sigma_{b}^{2}\right), \\
& f(c)=\pi_{0} f_{0}(c)+\pi_{1} f_{1}(c)
\end{aligned}
$$

where $\pi_{O}=$ proportion of true hits and $\pi_{1}=1-\pi_{0}$ [59]. The three quantities needed for the estimation of the false discovery rate, are estimated separately by using Maximum Likelihood, Poisson regression, and moment estimation. The estimation procedure is implemented in the function "locfdr" from the "locfdr" R-package [35].

\section{Data resampling to show that parallel screens add power}

We chose gene $g$ and pathogen $p$ for which we wanted to show the increase in power by simultaneously using the parallel screening structure. In our case, we repeated the analysis for three different cases, consisting of a unique hit (g: MET, p: L. monocytogenes), a shared hit ( $g:$ MTOR, $p$ : Vaccinia virus) and a non-hit ( $g$ : ALK, $p:$ B. abortus). Each time we resampled data for a fixed number of siRNAs $\left(n_{s}=2, \ldots, 11\right)$ and a fixed number of pathogens $\left(n_{p}=2, \ldots, 8\right)$ from the full dataset. In detail, we chose randomly $\left(n_{p}-1\right)$ pathogens and added additionally pathogen $p$. In the next step, we sampled $n_{s}$ siRNA sets from the full available set of siRNAs for every gene within all sampled pathogens. We applied PMM on the sampled data and we reported the rank of gene $g$ within pathogen $p$. This was repeated 
1000 times for each combination of $n_{s}$ and $n_{p}$. As a last step we calculated for each combination the mean and variance of the rank for gene $g$ within pathogen $p$. For the resampling we omitted genes that have less than 6 siRNA sets, in order to have a good resampling basis. Moreover, we applied the same procedure for the case of $n_{p}=1$ using MTT.

\section{Stability analysis}

We resampled with replacement 1000 datasets from the full data, taking for each gene the same number of siRNAs as in the full dataset. For each resampled dataset, PMM, MTT and RSA were applied and the corresponding ranking saved. For PMM the ranking was done according to the absolute value of the estimated $c_{p g}$ effects, for MTT we used the absolute values of the estimated mean and for RSA the ranking based on the $\log (p)$ values. We took absolute values to take into account down and up hits simultaneously. From the 1000 rankings we calculated the number of genes that appear with high probability (prob $>0.9$ and prob $>0.7$ ) in the top $k$ $(k=1, \ldots, 50)$ of the ranking.

\section{Hit overlaps examined by cross-validation}

For the hit cross-validation analysis we only used data coming from the siRNAs of all unpooled libraries (11 in total). In each run, we ran PMM, MTT, and RSA on a subset of the data consisting of 10 individual siRNAs and used the remaining siRNA set as test set. For PMM we ranked the results according to the absolute value of the estimated $c_{p g}$ effects, for MTT we did ranking with respect to the absolute values of the estimated mean, for RSA we based the ranking based on the $\log (p)$ values and for the test set we ordered the genes by the absolute value of infection score. We counted the number of genes that appeared in top $k(k=1, \ldots, 100)$ in both the training and test sets. We determined the counts separately for each pathogen and averaged them in the end.

\section{Data simulation and ROC-curves}

We simulated data by generating 1000 normally distributed screens (mean $=0$, std $=0.5$ ) for eight pathogens, taking 4 siRNAs each. Hits were incorporated in the simulated screens by randomly selecting about $10 \%$ of the genes ( 80 out of 826 ) and shifting them away from zero. The shift was determined by a uniformly distributed random variable. We used the interval [0.2,0.3] as parameter for the uniform distribution for "low shift" and the interval $[0.4,0.5]$ for "high shift". We distinguished between three cases: In the first case the hits were different for each pathogen (80 unique hits per pathogen), in the second case all hits were shared between the pathogens (same 80 hits for all pathogens) and in the third case we generated mixed hits (20 unique hits, 20 hits shared between two pathogens, 20 hits shared between four pathogens and 20 hits shared between all eight pathogens). PMM, MTT, and RSA were applied to the simulated data and the ranking was saved. For PMM the results were ranked according to the absolute value of the estimated $c_{p g}$ effects, for MTT the ranking was done with respect to the absolute values of the estimated mean and for RSA the ranking based on the $\log (p)$ values. For every ranking list we counted the number of true positives, true negatives, false positives and false negatives in the top $k(k=1, \ldots, 826)$ and computed the true positive rate $(\mathrm{TPR}=\mathrm{FP} /(\mathrm{FP}+\mathrm{TN}))$ and the false positive rate $(\mathrm{FPR}=\mathrm{FP} /(\mathrm{FP}+\mathrm{TN}))$.

\section{Influence of parallelism}

For selected pathogen $p$ we generated 1000 new datasets by fixing the data of $p$ and randomizing the data of the other 7 pathogens. We applied PMM to each dataset and saved the resulting ranking of $p$. In the next step we aggregated the 1000 rankings by taking the average over the $c_{p g}$ scores. We compared the averaged scores to the gene rankings obtained by PMM performed using the original dataset. We independently performed the study for each pathogen.

\section{Availability of supporting data}

The data sets supporting the results of this article are available on the InfectX openBIS data publication portal, that is located at http://www.infectx.ch/dataaccess/. The visitor username is "rdgr2014" and the corresponding password is "IXPubReview". The R-package PMM and related documentation is also available on this page.

\section{Additional file}

Additional file 1: Supplementary Information. The additional data file 1 contains supporting information und further analysis results.

\section{Abbreviations}

FDR: False discovery rate; GSEA: Gene set enrichment analysis; MTT: Moderated T-test; PMM: Parallel mixed model; ROC: Receiver operating characteristic; RSA: Redundant SiRNA Activity.

\section{Competing interests}

The authors declare that they have no competing interests.

\section{Authors' contributions}

We PR, AD, CA, NB, PC, ME, UG, W-DH, AH, CVM, LP, and CD planned experiments and analysis pipeline. HB-T, BC, RC, SE, CK, SK, AK, SHL, JM, DM, SM, JP-C, MT, and AY devised biological assays. GC, AK, SM, MS and AV plated siRNA libraries. HB-T, AC, RC, SE, CK, SK, AK, SHL, JM, DM, and SM performed siRNA screening. PR, $M E, P K, E P, M P, B R, V R, B S$, and LP contributed to the establishment of the computational analysis pipeline. ME, CK, MT, and AV planned image acquisition. ME with support of GS and EP performed image analysis and data management. PR with support of ME, NB, AD, FS, JS, ES, and CVM normalized image-derived data. PR and AD with support of NB, PB, FS, JS, and ES performed statistical analysis. $A D$ and $P B$ developed the PMM method. The manuscript was written by $P R, A D$, and $C D$. All authors read and approved the final manuscript. 


\section{Acknowledgements}

We acknowledge support by grants 51RT 0_126008 and 51RTP0_151029 for the Research and Technology Development (RTD) projects InfectX and TargetinfectX, respectively, in the frame of SystemsX.ch, the Swiss Initiative for Systems Biology. C.D. acknowledges grant 31003A-132979 from the Swiss National Science Foundation (SNSF) and ERC advanced grant 340330. P.C. would like to acknowledge the following grants: ERC advanced grant 233348, ANR grant MIE-2009-SignRupVac, Fondation Le Roch and Fondation Jeantet. A.K. is a recipient of a scholarship from the Pasteur-Paris University International Doctoral Program/Institut Carnot Maladies Infectieuses. E.S. was supported by the ETH Zurich Postdoctoral Fellowship Program and the Marie Curie Actions for People COFUND program (grant No. FEL-13 12-1) (to E.S. and N.B.). F.S. has been supported by SystemsX ch, the Swiss initiative in systems biology, under IPhd grant No. 2009/025 (to N. B.). Work of S.H.L and A.C. was supported by the International PhD Program "Fellowships for Excellence" of the Biozentrum. The work on Adenovirus and Rhinovirus screening infrastructure was supported by grant SystemsX PhD, grant Novartis: Stiftung für Medizinisch-Biologische Forschung and University of Zurich: Bauten und Investitionen. Work in the Greber lab was funded by a grant from the SNSF (31003A_141222/1) and an iPhD fellowship to partly support A.Y. (SXPHIO_142001/1). We acknowledge support from Dr. A. Jurgeit in the development of the Rhinovirus infection assay. We thank Dr. Jean Pierre Gorvel (Centre d'immunolgie de Marseille-Luminy, Marseille, France) for kindly providing B. abortus GFP strain. We wish to thank Rainer Pöhlmann (Biozentrum, University of Basel, Switzerland) and Konstantin Arnold (Biozentrum, University of Basel and Swiss Institute of Bioinformatics), as well as the [BC]2 Basel Computational Biology Center for support and provision of high-performance computing resources. We acknowledge openBIS / CISD and Ramakrishnan Chandrasekhar, who implemented many extensions and modifications in screening openBIS

\section{Author details}

${ }^{1}$ Focal Area Infection Biology, Biozentrum, University of Basel, Klingelberstrasse 70, CH-4056 Basel, Switzerland. '2 Seminar for Statistics, ETH Zurich, Zurich, Switzerland. ${ }^{3}$ Institute of Molecular Life Sciences, University of Zurich, Zurich, Switzerland. ${ }^{4}$ Department of Biosystems Science and Engineering, ETH Zurich, Zurich, Switzerland. ${ }^{5}$ Swiss Institute of Bioinformatics, Basel, Switzerland. Institut Pasteur, Unité des Interactions Bactéries Cellules; INSERM, U604; INRA, USC2020, Paris, France. ${ }^{7}$ Institute for Tropical Health and Departamento de Microbiología y Parasitología, Universidad de Navarra, Pamplona, Spain. ${ }^{8}$ Institute of Biochemistry, ETH Zurich, Zurich, Switzerland. 'Department of Biology, Institute of Microbiology, ETH Zurich, Zurich, Switzerland. ${ }^{10}$ Institute of Molecular Biology, Mainz, Germany. "'Light Microscopy and Screening Center, ETH Zurich, Zurich, Switzerland. ${ }^{12}$ Research IT, Biozentrum, University of Basel, Basel, Switzerland. ${ }^{13}$ Institut Cochin, INSERM U1016, CNRS 8104, Université Paris Descartes, Paris, France. ${ }^{14}$ SyBIT, SystemsX.ch, Zurich, Switzerland.

Received: 11 July 2014 Accepted: 12 December 2014 Published: 22 December 2014

\section{References}

1. Conrad C, Gerlich DW: Automated microscopy for high-content RNAi screening. J Cell Biol 2010, 188(4):453-461.

2. Mohr S, Bakal C, Perrimon N: Genomic screening with RNAi: results and challenges. Annu Rev Biochem 2010, 79:37-64.

3. Mohr SE, Perrimon N: RNAi screening: new approaches, understandings, and organisms. Wiley Interdiscip Rev RNA 2012, 3(2):145-158.

4. Simpson KJ, Davis GM, Boag PR: Comparative high-throughput RNAi screening methodologies in $\mathrm{C}$. elegans and mammalian cells. N Biotechnol 2012, 29(4):459-470.

5. Elbashir SM, Harborth J, Lendeckel W, Yalcin A, Weber K, Tuschl T: Duplexes of 21-nucleotide RNAs mediate RNA interference in cultured mammalian cells. Nature 2001, 411(6836):494-498.

6. Mercer J, Snijder B, Sacher R, Burkard C, Bleck CK, Stahlberg H, Pelkmans L, Helenius A: RNAi screening reveals proteasome- and cullin3-dependent stages in vaccinia virus infection. Cell Rep 2012, 2(4):1036-1047.

7. Stertz S, Shaw ML: Uncovering the global host cell requirements for influenza virus replication via RNAi screening. Microbes Infect 2011, 13(5):516-525.

8. Misselwitz B, Dilling S, Vonaesch P, Sacher R, Snijder B, Schlumberger M, Rout S, Stark M, von Mering C, Pelkmans L, Hardt WD: RNAi screen of
Salmonella invasion shows role of COPI in membrane targeting of cholesterol and Cdc42. Mol Syst Biol 2011, 7:474.

9. Snijder B, Sacher R, Ramo P, Liberali P, Mench K, Wolfrum N, Burleigh L, Scott CC, Verheije MH, Mercer J, Moese S, Heger T, Theusner K, Jurgeit A, Lamparter D, Balistreri G, Schelhaas M, De Haan CAM, Marjomäki V, Hyypiä T, Rottier PJM, Sodeik B, Marsh M, Gruenberg J, Amara A, Greber U, Helenius A, Pelkmans L: Single-cell analysis of population context advances RNAi screening at multiple levels. Mol Syst Biol 2012, 8:579.

10. Schmidt EE, Pelz O, Buhlmann S, Kerr G, Horn T, Boutros M: GenomeRNAi: a database for cell-based and in vivo RNAi phenotypes, 2013 update. Nucleic Acids Res 2013, 41(Database issue):D1021-D1026.

11. Pache L, Konig R, Chanda SK: Identifying HIV-1 host cell factors by genome-scale RNAi screening. Methods 2011, 53(1):3-12.

12. Sigoillot FD, King RW: Vigilance and validation: keys to success in RNAi screening. ACS Chem Biol 2011, 6(1):47-60

13. Bushman FD, Malani N, Fernandes J, D'Orso I, Cagney G, Diamond TL, Zhou H, Hazuda DJ, Espeseth AS, König R, Bandyopadhyay S, Ideker T, Goff SP, Krogan NJ, Frankel AD, Young JA, Chanda SK: Host cell factors in HIV replication: meta-analysis of genome-wide studies. PLoS Pathog 2009, 5(5):e1000437.

14. Heynen-Genel S, Pache L, Chanda SK, Rosen J: Functional genomic and high-content screening for target discovery and deconvolution. Expert Opin Drug Discov 2012, 7(10):955-968.

15. Sivan G, Martin SE, Myers TG, Buehler E, Szymczyk KH, Ormanoglu P, Moss B: Human genome-wide RNAi screen reveals a role for nuclear pore proteins in poxvirus morphogenesis. Proc Natl Acad Sci U S A 2013, 110(9):3519-3524.

16. Buehler E, Chen YC, Martin S: C911: A bench-level control for sequence specific siRNA off-target effects. PLoS One 2012, 7(12):e51942.

17. Bassik MC, Kampmann M, Lebbink RJ, Wang S, Hein MY, Poser I, Weibezahn J, Horlbeck MA, Chen S, Mann M, Hyman AA, Leproust EM, McManus MT, Weissman JS: A systematic mammalian genetic interaction map reveals pathways underlying ricin susceptibility. Cell 2013, 152(4):909-922.

18. Kittler R, Surendranath V, Heninger AK, Slabicki M, Theis M, Putz G, Franke K, Caldarelli A, Grabner H, Kozak K, Wagner J, Rees E, Korn B, Frenzel C, Sachse C, Sönnichsen B, Guo J, Schelter J, Burchard J, Linsley PS, Jackson AL, Habermann B, Buchholz F: Genome-wide resources of endoribonucleaseprepared short interfering RNAs for specific loss-of-function studies. Nat Methods 2007, 4(4):337-344.

19. Collinet C, Stoter M, Bradshaw CR, Samusik N, Rink JC, Kenski D, Habermann B, Buchholz F, Henschel R, Mueller MS, Nagel WE, Fava E, Kalaidzidis Y, Zerial M: Systems survey of endocytosis by multiparametric image analysis. Nature 2010, 464(7286):243-249.

20. Marine $S$, Bahl A, Ferrer M, Buehler E: Common seed analysis to identify off-target effects in siRNA screens. J Biomol Screen 2012, 17(3):370-378,

21. Buehler E, Khan AA, Marine S, Rajaram M, Bahl A, Burchard J, Ferrer M: siRNA off-target effects in genome-wide screens identify signaling pathway members. Sci Rep 2012, 2:428.

22. Sigoillot FD, Lyman S, Huckins JF, Adamson B, Chung E, Quattrochi B, King RW: A bioinformatics method identifies prominent off-targeted transcripts in RNAi screens. Nat Methods 2012, 9(4):363-366.

23. Dehio C, Meyer M, Berger J, Schwarz H, Lanz C: Interaction of Bartonella henselae with endothelial cells results in bacterial aggregation on the cell surface and the subsequent engulfment and internalisation of the bacterial aggregate by a unique structure, the invasome. J Cell Sci 1997 . 110(Pt 18):2141-2154.

24. Cossart P, Sansonetti PJ: Bacterial invasion: the paradigms of enteroinvasive pathogens. Science 2004, 304(5668):242-248.

25. Meier O, Boucke K, Hammer SV, Keller S, Stidwill RP, Hemmi S, Greber UF: Adenovirus triggers macropinocytosis and endosomal leakage together with its clathrin-mediated uptake. J Cell Biol 2002, 158(6):1119-1131.

26. Mercer J, Helenius A: Vaccinia virus uses macropinocytosis and apoptotic mimicry to enter host cells. Science 2008, 320(5875):531-535.

27. Malo N, Hanley JA, Cerquozzi S, Pelletier J, Nadon R: Statistical practice in high-throughput screening data analysis. Nat Biotechnol 2006, 24(2):167-175.

28. Carpenter AE, Jones TR, Lamprecht MR, Clarke C, Kang IH, Friman O, Guertin DA, Chang JH, Lindquist RA, Moffat J, Golland P, Sabatini DM: Cell profiler: image analysis software for identifying and quantifying cell phenotypes. Genome Biol 2006, 7(10):R100

29. Birmingham A, Selfors LM, Forster T, Wrobel D, Kennedy CJ, Shanks E, SantoyoLopez J, Dunican DJ, Long A, Kelleher D, Smith Q, Beijersbergen RL, Ghazal P, 
Shamu CE: Statistical methods for analysis of high-throughput RNA interference screens. Nat Methods 2009, 6(8):569-575.

30. Siebourg J, Merdes G, Misselwitz B, Hardt WD, Beerenwinkel N: Stability of gene rankings from RNAi screens. Bioinformatics 2012, 28(12):1612-1618.

31. Snijder B, Pelkmans L: Origins of regulated cell-to-cell variability. Nat Rev Mol Cell Biol 2011, 12(2):119-125.

32. Rouilly V, Pujadas E, Hullar B, Balazs C, Kunszt P, Podvinec M: iBRAIN2: automated analysis and data handling for RNAi screens. Stud Health Technol Inform 2012, 175:205-213.

33. Pinheiro JC, Bates DM: Mixed-Effects Models in S and S-PLUS. New York: Springer; 2000.

34. Bates D, Maechler M, Bolker B: Ime4: Linear Mixed-Effects Models Using S4 Classes. 2013. http://cran.r-project.org/package=Ime4.

35. Efron B, Turnbull BB, Narasimhan B: locfdr: Computes Local False Discovery Rates. 2011. http://cran.r-project.org/package=locfdr.

36. Smyth GK: Linear models and empirical bayes methods for assessing differential expression in microarray experiments. Stat Appl Genet Mol Biol 2004, 3:Article3.

37. Pizarro-Cerda J, Kuhbacher A, Cossart P: Entry of listeria monocytogenes in Mammalian Epithelial Cells: an updated view. Cold Spring Harbor Perspect Med 2012, 2:11

38. Tattoli I, Philpott DJ, Girardin SE: The bacterial and cellular determinants controlling the recruitment of mTOR to the Salmonella-containing vacuole. Biol Open 2012, 1(12):1215-1225.

39. Konig R, Chiang CY, Tu BP, Yan SF, DeJesus PD, Romero A, Bergauer T, Orth A, Krueger U, Zhou Y, Chanda SK: A probability-based approach for the analysis of large-scale RNAi screens. Nat Methods 2007, 4(10):847-849.

40. Zhang XD, Ferrer M, Espeseth AS, Marine SD, Stec EM, Crackower MA, Holder DJ, Heyse JF, Strulovici B: The use of strictly standardized mean difference for hit selection in primary RNA interference high-throughput screening experiments. J Biomol Screen 2007, 12(4):497-509.

41. Meinshausen N, Bühlmann P: Stability selection. J R Stat Soc Ser B (Statistical Methodology) 2010, 72(4):417-473.

42. Subramanian A, Tamayo P, Mootha VK, Mukherjee S, Ebert BL, Gillette MA, Paulovich A, Pomeroy SL, Golub TR, Lander ES, Mesirov JP: Gene set enrichment analysis: a knowledge-based approach for interpreting genome-wide expression profiles. Proc Natl Acad Sci U S A 2005, 102(43):15545-15550.

43. Szklarczyk D, Franceschini A, Kuhn M, Simonovic M, Roth A, Minguez P, Doerks T, Stark M, Muller J, Bork P, Jensen $\sqcup$, von Mering C: The STRING database in 2011: functional interaction networks of proteins, globally integrated and scored. Nucleic Acids Res 2011, 39(Database issue):D561-D568.

44. Elfaki MG, Al-Hokail AA: Transforming growth factor beta production correlates with depressed lymphocytes function in humans with chronic brucellosis. Microbes Infect 2009, 11(14-15):1089-1096.

45. Shen Y, Naujokas K, Park M, Ireton K: InlB-dependent internalization of Listeria is mediated by the Met receptor tyrosine kinase. Cell 2000, 103(3):501-510.

46. Zheng K, Chen DS, Wu YQ, Xu XJ, Zhang H, Chen CF, Chen HC, Liu ZF: MicroRNA expression profile in RAW264.7 cells in response to Brucella melitensis infection. Int J Biol Sci 2012, 8(7):1013-1022.

47. Qin QM, Pei J, Ancona V, Shaw BD, Ficht TA, de Figueiredo P: RNAi screen of endoplasmic reticulum-associated host factors reveals a role for IRE1alpha in supporting Brucella replication. PLoS Pathog 2008, 4(7):e1000110.

48. Cain RJ, Vanhaesebroeck B, Ridley AJ: The PI3K p110alpha isoform regulates endothelial adherens junctions via Pyk2 and Rac1. J Cell Biol 2010, 188(6):863-876.

49. Kakumoto T, Nakata T: Optogenetic control of PIP3: PIP3 is sufficient to induce the actin-based active part of growth cones and is regulated via endocytosis. PLoS One 2013, 8(8):e70861.

50. Grassme H, Riehle A, Wilker B, Gulbins E: Rhinoviruses infect human epithelial cells via ceramide-enriched membrane platforms. J Biol Chem 2005, 280(28):26256-26262.

51. Sessions OM, Barrows NJ, Souza-Neto JA, Robinson TJ, Hershey CL, Rodgers MA, Ramirez JL, Dimopoulos G, Yang PL, Pearson JL, Garcia-Blanco MA: Discovery of insect and human dengue virus host factors. Nature 2009, 458(7241):1047-1050.

52. Suomalainen M, Luisoni S, Boucke K, Bianchi S, Engel DA, Greber UF: A direct and versatile assay measuring membrane penetration of adenovirus in single cells. J Virol 2013, 87(22):12367-12379
53. Yakimovich A, Gumpert H, Burckhardt CJ, Lutschg VA, Jurgeit A, Sbalzarini IF, Greber UF: Cell-free transmission of human adenovirus by passive mass transfer in cell culture simulated in a computer model. J Virol 2012, 86(18):10123-10137.

54. Dehio $M$, Knorre A, Lanz C, Dehio C: Construction of versatile high-level expression vectors for Bartonella henselae and the use of green fluorescent protein as a new expression marker. Gene 1998, 215(2):223-229.

55. Celli J, Salcedo SP, Gorvel JP: Brucella coopts the small GTPase Sar1 for intracellular replication. Proc Natl Acad Sci U S A 2005, 102(5):1673-1678.

56. Jurgeit A, Moese S, Roulin P, Dorsch A, Lotzerich M, Lee WM, Greber UF: An RNA replication-center assay for high content image-based quantifications of human rhinovirus and coxsackievirus infections. Virol J 2010, 7:264.

57. Jurgeit A, McDowell R, Moese S, Meldrum E, Schwendener R, Greber UF: Niclosamide is a proton carrier and targets acidic endosomes with broad antiviral effects. PLoS Pathog 2012, 10:8.

58. Mosser AG, Brockman-Schneider R, Amineva S, Burchell L, Sedgwick JB, Busse WW, Gern JE: Similar frequency of rhinovirus-infectible cells in upper and lower airway epithelium. J Infect Dis 2002, 185(6):734-743.

59. Efron B: Large-Scale Inference : Empirical Bayes Methods for Estimation, Testing, and Prediction. Cambridge: Cambridge University Press; 2010.

doi:10.1186/1471-2164-15-1162

Cite this article as: Rämö et al:: Simultaneous analysis of large-scale RNAi screens for pathogen entry. BMC Genomics 2014 15:1162.

\section{Submit your next manuscript to BioMed Central and take full advantage of:}

- Convenient online submission

- Thorough peer review

- No space constraints or color figure charges

- Immediate publication on acceptance

- Inclusion in PubMed, CAS, Scopus and Google Scholar

- Research which is freely available for redistribution 